\title{
Mechanochemical regulation of growth cone motility
}

\author{
Patrick C. Kerstein, Robert H. Nichol IV and Timothy M. Gomez* \\ Neuroscience Training Program, Department of Neuroscience, School of Medicine and Public Health, \\ University of Wisconsin-Madison, Madison, WI, USA
}

Neuronal growth cones are exquisite sensory-motor machines capable of transducing features contacted in their local extracellular environment into guided process extension during development. Extensive research has shown that chemical ligands activate cell surface receptors on growth cones leading to intracellular signals that direct cytoskeletal changes. However, the environment also provides mechanical support for growth cone adhesion and traction forces that stabilize leading edge protrusions. Interestingly, recent work suggests that both the mechanical properties of the environment and mechanical forces generated within growth cones influence axon guidance. In this review we discuss novel molecular mechanisms involved in growth cone force production and detection, and speculate how these processes may be necessary for the development of proper neuronal morphogenesis.

OPEN ACCESS

Edited by: Daniel Marcel Suter, Purdue University, USA

Reviewed by: Laura Anne Lowery, Boston College, USA Stephanie L. Gupton, University of North Carolina at Chapel Hill, USA

${ }^{*}$ Correspondence: Timothy M. Gomez, Neuroscience Training Program, Department of Neuroscience, School of Medicine and Public Health, University of Wisconsin-Madison, 1111 Highland Avenue, Madison, WI 53705, USA tmgomez@wisc.edu

Received: 08 May 2015 Accepted: 16 June 2015 Published: 07 July 2015

Citation:

Kerstein PC, Nichol RHIV and Gomez TM (2015) Mechanochemical regulation of growth cone motility.

Front. Cell. Neurosci. 9:244. doi: 10.3389/fncel.2015.00244
Keywords: mechanotransduction, axon guidance, TRP channels, substrate rigidity, durotaxis, actin retrograde flow, neuron

\section{Biochemical and Mechanical Signal Cross-talk in Growth Cones}

The last two decades of intensive research have identified many families of chemical ligands and corresponding receptors that are required for proper neural network assembly during embryonic development (for review, see Chèdotal and Richards, 2010; Kolodkin and Tessier-Lavigne, 2011). Previous studies in several animal models clearly demonstrate that graded chemical ligands deposited in the environment of developing neurons serve as navigational cues that guide neuronal migration and morphogenesis. Soluble, cell surface and substratum-associated extracellular ligands are known to activate receptors linked to numerous intracellular biochemical signal transduction cascades that regulate motility. Most biochemical signals effect cytoskeletal dynamics and membrane trafficking directly, or indirectly through new protein translation, to control growth cone motility (Vitriol and Zheng, 2012; Shigeoka et al., 2013). Receptors on growth cones for growth factors, guidance cues and adhesive ligands activate signals that both promote and inhibit motility. A diverse and complex web of interacting biochemical signals are activated by individual ligands. Signaling is further complicated in vivo, where multiple ligands are encountered concurrently and signals are integrated by growth cones and converted into a proper behavioral output (Dudanova and Klein, 2013).

While chemical cues in the environment quite clearly have complex and varied effects on intracellular signaling, new work shows that the mechanical properties of the cellular micro-environment of developing neurons also influence signaling and motility. Immobilized ligands on cell surfaces or secreted into the extracellular environment provide adhesive support for migrating cells. Cell surface receptors physically link to immobilized ligands with varying affinities (Myers et al., 2011; Hynes and Naba, 2012). Molecular 
adaptor proteins link receptors to rigid cytoskeletal elements that generate opposing forces. Classic studies showed that growing axons produce both contractile (myosin motor driven) and pushing (cytoskeleton polymerization) forces (Letourneau et al., 1987; Lamoureux et al., 1989; Heidemann et al., 1990). These forces are known to reciprocally influence cell signaling as a feedback homeostatic regulator of cell adhesion, shape and movements. Therefore, there is likely complex cross talk between biochemical and mechanical signaling within motile growth cones. In this review, we discuss our current understanding on roles of the mechanical environment and intracellular forces that govern axon guidance.

\section{Mechanical Force Generation by Growth Cones}

The cytomechanical forces that control growth cone motility have been intensely studied for the last 30 years, yet our understanding is still incomplete. Similar to non-neuronal cells, actin and microtubule polymerization play central roles as forcegenerating polymers in axonal growth cones (Figure 1). Complex mechanisms function within growth cones downstream of chemical and mechanical signals to tightly regulate the dynamic assembly and organization of the cytoskeleton (Lowery and van Vactor, 2009; Dent et al., 2011). Leading edge protrusion is thought to be driven largely by F-actin polymerization. Actin polymerization at the leading edge produces tensile forces, which are distributed between plasma membrane protrusion and rearward movement of F-actin bundles (Symons and Mitchison, 1991; Lin et al., 1996; Mogilner and Oster, 2003; Carlier and Pantaloni, 2007). Balance between membrane fluid dynamics and F-actin tensile strength may contribute to the extent of forward protrusion vs. rearward flow of F-actin (Figure 1; Bornschlögl, 2013). Conversely, ADF-cofilin mediated depolymerization of $\mathrm{F}$-actin minus ends relieves compressive actin network forces and replenishes G-actin pools needed for further F-actin polymerization at the leading edge (Bamburg, 1999; Marsick et al., 2010; Zhang et al., 2012). A second force that powers F-actin retrograde flow (RF) is myosin-II motor dimers, which centripetally contract antiparallel F-actin networks toward the growth cone central domain (Turney and Bridgman, 2005; Medeiros et al., 2006; Yang et al., 2013; Shin et al., 2014). The contractile force of myosin-II, coupled with the rearward flow of F-actin due to leading edge polymerization, drives F-actin RF in growth cones (Forscher and Smith, 1988; Lin and Forscher, 1995; Brown and Bridgman, 2003). Other F-actin motor proteins, such as myosin I (Wang et al., 2003), V, VI (Suter et al., 2000; Kubota et al., 2010), and X (Berg and Cheney, 2002), also contribute to growth cone movements, morphology and vesicle trafficking.

During axon development and guidance, the equilibrium between actin polymerization and $\mathrm{RF}$ is a key regulator of growth cone protrusion and retraction. Increased leading edge protrusion could theoretically result from either increased actin polymerization or decreased myosin-II contraction. On the other hand, leading edge retraction or collapse could result from reduced actin polymerization, increased depolymerization,

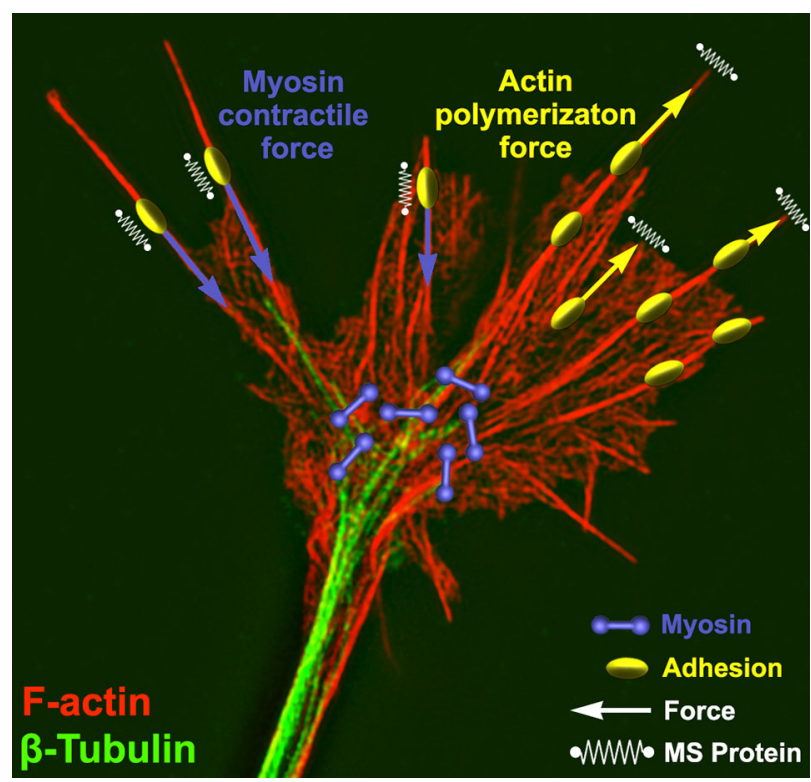

FIGURE 1 | Force generation and force sensing in neuronal growth cones. A neuronal growth cone is labeled for filamentous actin (red) and $\beta \mathrm{I}-\|$ tubulin (green) using immunocytochemistry. This super resolution image was captured using structure illumination microscopy as previously described (Santiago-Medina et al., 2015). Overlaying the image are schematic elements depicting myosin dimers (purple) and adhesion complexes (yellow) near the central and peripheral growth cone, respectively. Myosin bound to actin produces a rearward force (purple arrows) on adhesion complexes where mechanosensitive (MS) proteins (parallel springs) detect this force. Adhesion complexes antagonize this rearward force allowing actin polymerization to expand the leading edge membrane (yellow arrows) and stretching a set of membrane MS proteins (perpendicular springs).

or increased myosin-II contraction. Another key force that counteracts RF in growth cones, as in non-neuronal cells (Smilenov et al., 1999; Giannone et al., 2009; Thievessen et al., 2013), are clutching forces at cell-substratum adhesions, which physically link to the F-actin cytoskeleton through a number of adaptor and signaling proteins (Suter et al., 1998; Woo and Gomez, 2006; Bard et al., 2008; Shimada et al., 2008; Myers and Gomez, 2011; Santiago-Medina et al., 2013; Toriyama et al., 2013). The molecular "clutch" is thought to restrain myosinII mediated contractile forces upon the F-actin network to redirect the force of actin polymerization toward membrane protrusion. Many signaling and adaptor proteins target to growth cone point contact adhesions to regulate clutching, which provide numerous possible sites for regulatory control of axon guidance downstream of soluble, immobilized, and mechanical cues (Bard et al., 2008; Myers and Gomez, 2011; Toriyama et al., 2013).

Growth cone point contact adhesions are related to fibroblast focal adhesions, which are multi-functional, macromolecular protein complexes (Smilenov et al., 1999; Bard et al., 2008; Shimada et al., 2008; Geiger et al., 2009; Giannone et al., 2009; Toriyama et al., 2013). However, much less is understood about the molecular regulation and function of growth cone adhesions, and it is likely that these adhesions serve many functions that 
are unique to growth cones. Point contact adhesions typically assemble within growth cone filopodia that contain parallel bundled actin, have a short lifetime, then disassemble near the base of filopodia (Figure 2). Point contact adhesions appear to require integrin engagement, as they are observed primarily in growth cones on extracellular matrix (ECM) proteins (Woo and Gomez, 2006; Myers and Gomez, 2011). The ECM contains many ligands that modulate growth cone motility, such as laminin, tenascin, fibronectin, etc. Each type of ECM ligand activates specific integrin receptors, as we have recently reviewed (Myers et al., 2011). Activation of integrins leads to recruitment of scaffolding and signaling proteins, such as talin, focal adhesion kinase (FAK), paxillin, zyxin, and $\alpha$-actinin (Gomez et al., 1996; Cluzel et al., 2005; Robles and Gomez, 2006; Myers et al., 2011). In non-neuronal cells, scaffolding proteins link to actin filaments to clutch RF, which supports actin polymerization to drive protrusion of the leading edge (Smilenov et al., 1999; Giannone et al., 2009; Thievessen et al., 2013). Similar clutching of RF likely occurs at growth cone point contacts (Santiago-Medina et al., 2013) and higher density adhesions have been linked to slower RF (Koch et al., 2012). Importantly, since point contact adhesions are modulated by ECM and soluble guidance factors (Woo and Gomez, 2006; Myers and Gomez, 2011; Myers et al., 2012), it is plausible that growth cone guidance is controlled by local changes in RF. Indeed, early studies from Paul Forscher and colleagues suggested that local reduction in RF is correlated with increased growth cone motility (Lin and Forscher, 1995; Lin et al., 1996; Santiago-Medina et al., 2013). For example, reduced $\mathrm{RF}$ is correlated with translocation of the growth cone central domain toward areas of strong adhesion of Aplysia neurons in contact with ApCAM-coated beads (Lin and Forscher, 1995; Suter et al., 1998). While the adapter proteins that link and clutch F-actin differ between cell adhesion molecules, such as
ApCAM, L1 and N-cadherin, and integrin-ECM adhesions, they both function to restrain RF and promote axon outgrowth (Lin and Forscher, 1995; Suter et al., 1998; Bard et al., 2008; Toriyama et al., 2013).

The inverse relationship between RF and growth cone motility is well established, however there are exceptions to this model. For example, actin RF and motility both increase in Aplysia growth cones stimulated with 5-HT (5-hydroxytryptamine, serotonin; Zhang et al., 2012). This difference may be stimulus dependent, as 5-HT may increase actin polymerization without modulating adhesion dynamics leading to increase actin drag on existing adhesions. This has been described as the viscous slip clutch model (Giannone et al., 2009; Zhang et al., 2012). Conversely, guidance cues such as brain-derived neurotrophic factor (BDNF) and Semaphorin $3 \mathrm{~A}$ regulate traction forces and actin RF speeds by changing adhesion dynamics (Woo and Gomez, 2006; Myers and Gomez, 2011). However, it is still unclear whether these two mechanisms operate within individual cells, but work in epithelial cells suggests RF rates may slow at focal adhesions through clutching and increases at the leading edge through increased actin polymerization (Gardel et al., 2008). It remains unclear how clutching mechanisms in growth cones depend upon the adhesive environment, soluble guidance cues and cell type.

Increased protrusive forces at the leading edge membrane generated by molecular clutching of F-actin RF, are balanced by adhesive (traction) forces with the cell substratum at adhesion sites (Figure 3). Traction forces with the cell substratum have been measured in migrating cells and growth cones using deformable substrata containing fluorescent tracer beads as fiducial marks (Hyland et al., 2014). Early work showed that cells migrate in the direction of the strongest substratum forces
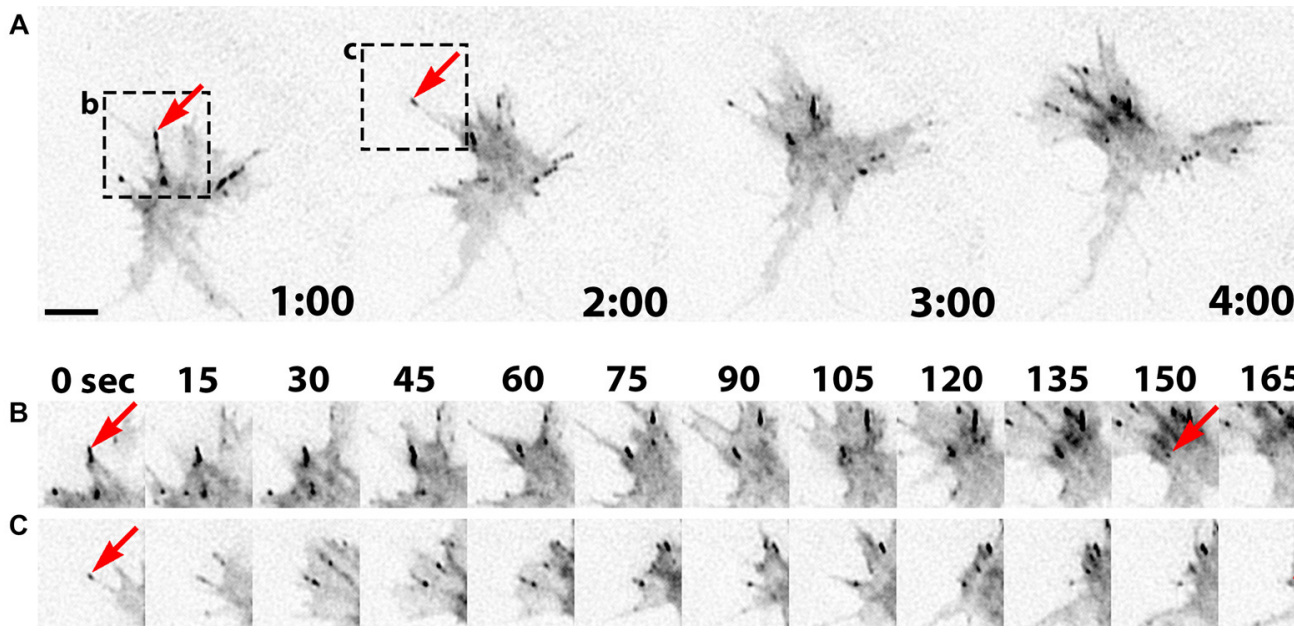

FIGURE 2 | Point contact adhesion dynamics in neuronal growth cones. (A) Inverted contrast images of a Xenopus growth cone expressing Paxillin-GFP captured every 1 min over a 4 min period using TIRF microscopy. The arrows and black boxes denote the adhesions viewed in (B) and $\mathbf{( C )}$. (B,C) Images of individual adhesions are displayed

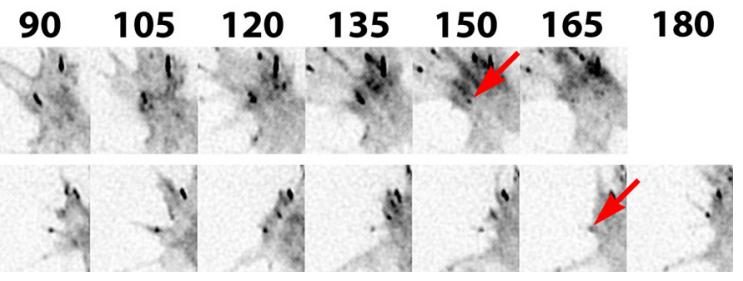

at $15 \mathrm{~s}$ intervals. The arrows indicate the first and last frames of specific paxillin-GFP puncta. This figure was created with an original timelapse captured for demonstration purposes in this manuscript using techniques previously described (Woo et al., 2009; Myers and Gomez, 2011). Scale bar, $5 \mu \mathrm{m}$ for all panels. 


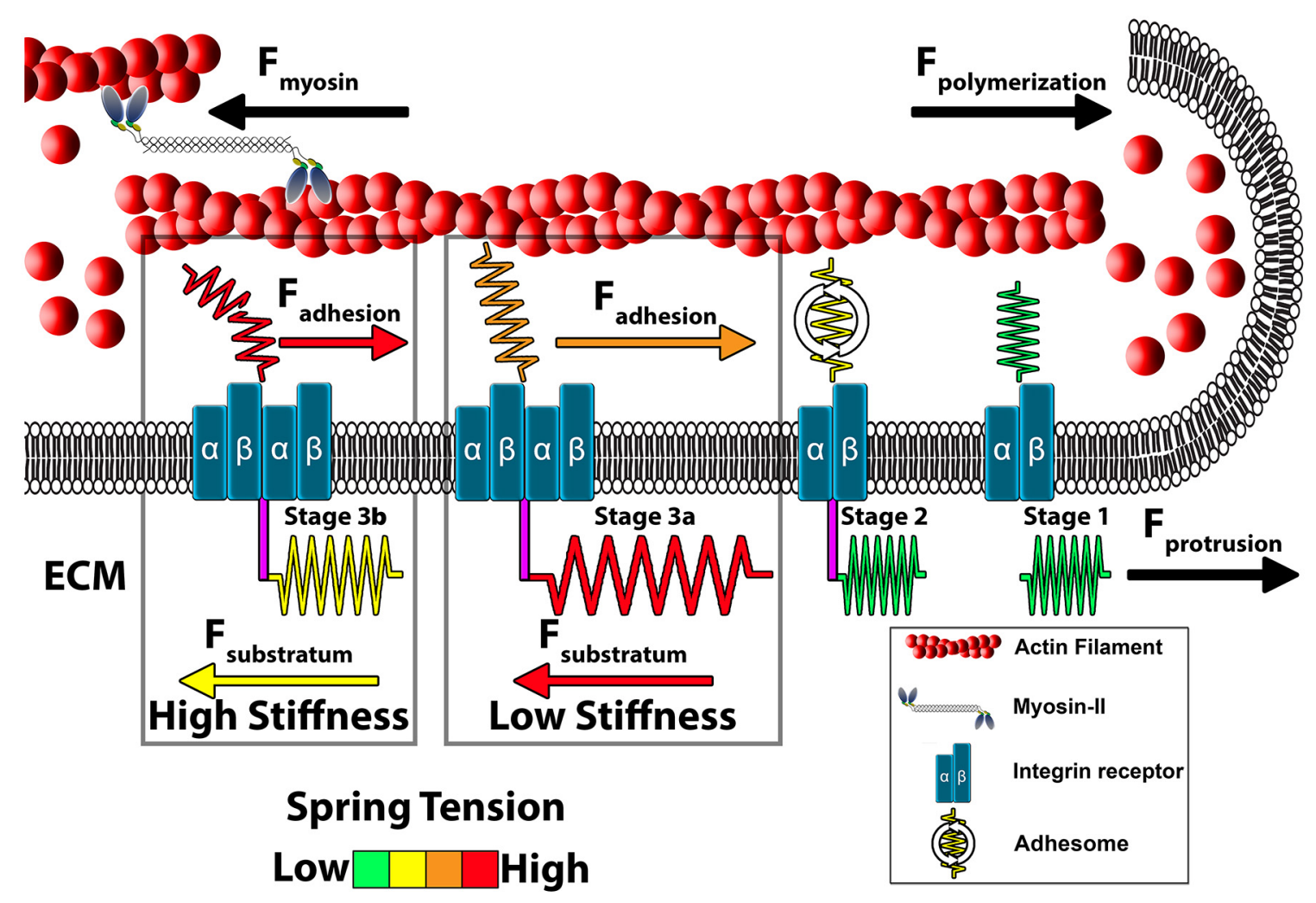

FIGURE 3 | Model of growth cone traction forces on high and low compliant substrata. Distal to the leading edge, active myosin-II generates contractile forces ( $\left.F_{\text {myosin }}\right)$ that pulls $F$-actin rearward. In addition, actin polymerization at the leading edge pushes against the plasma membrane to propel $F$-actin rearward $\left(F_{\text {polymerization }}\right)$. These forces integrate to drive constitutive retrograde flow (RF) of F-actin filaments at the leading edge. Stage 1 (ligand unbound). The molecular clutch is disengaged in the absence of integrin activation and clustering leading to rapid RF due to unrestrained

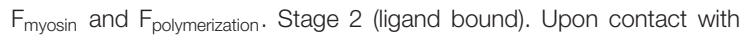
extracellular matrix (ECM) proteins, integrin receptors become activated, cluster and begin recruiting adhesome-related adaptor and signaling proteins. Stage 3 (clutching). Mature point contact adhesions link with actin filaments ( $\left.F_{\text {adhesion }}\right)$ to restrict $R F$ and generate traction forces $\left(F_{\text {traction }}\right)$ on the substratum. Therefore, forces generated by clutching of RF are distributed between traction forces with the ECM, adhesive forces on point contacts and protrusive forces at the leading edge. Conditions that maintain clutching of RF produce robust protrusion. Stage 3a (low substratum stiffness). On soft substrata, $F_{\text {traction }}$ forces are distributed to the elastic substrata at point contact adhesions through substratum displacement, which reduces $F_{\text {adhesion }}$ at point contact adhesions. Lower $F_{\text {adhesion }}$ at point contacts prevents clutch slippage (breaking), leading to increased protrusion and growth cone translocation. Stage 3b (high stiffness). Little displacement of the ECM occurs on rigid substrata. Subsequently, most force of RF is transferred to $F_{\text {adhesion }}$ at point contacts during clutching. The increased force on adhesions results in breaking or disassembly of point contacts via molecular stretching or activation of cellular signals. Fewer and short lived point contacts on rigid ECM disrupts clutching forces necessary for membrane protrusion and rapid outgrowth.
(Lo et al., 2000), which occur at focal adhesions (Plotnikov et al., 2012). In growth cones, these traction forces on the substratum are distributed within the actin-rich peripheral domain, where point contact adhesions are formed (Figure 1; Hyland et al., 2014). In response to guidance cues, localized assembly of adhesion complexes likely yield a redistribution of the traction forces on the substratum. This differential increase in traction forces on one side of the growth cone results in preferential growth in that direction. Moreover, the strength of traction forces generated by cells and growth cones increases on more rigid substrata, suggesting homeostatic regulation of force production (Chan and Odde, 2008; Koch et al., 2012). Substratum elasticity regulates integrin activity, internalization and adhesion site assembly (Du et al., 1993; Friedland et al., 2009), which likely accounts for increased traction forces at higher rigidity. Interestingly, growth cones from different neuronal types have been shown to generate different levels of substratum traction stress. For example, CNS hippocampal neurons exhibit rapid RF rates, due to decreased clutching, and can only generate modest peak traction stress. Conversely, dorsal root ganglion (DRG) neurons, which form more point contact adhesions that slow RF, can generate larger traction forces (Koch et al., 2012). These differences in traction stress may be related to the types of elastic environments CNS vs. PNS neurons encounter.

\section{Mechanically Sensitive Proteins within Neuronal Growth Cones}

For cells to sense the mechanical properties of their environment they must express proteins that change their conformation in response to mechanical force or tension. Depending on the type of mechanosensitive (MS) protein, conformational changes 
may lead to modulation of enzymatic activity, accessibility of binding sites for protein-protein interactions, or regulation of ion channel gating. One site where cell mechanosensors are likely concentrated is at integrin receptor-adhesion protein complexes, which function at the interface between the cytoskeleton and ECM (Figure 4). Adhesion complexes are spatially and temporally regulated by mechanical strain and substrate elasticity (Pelham and Wang, 1997; Schedin and Keely, 2011), suggesting they provide homeostatic feedback, termed tensional homeostasis. In this section we will discuss several recent reports that demonstrate that individual adhesion proteins and MS ion channels can respond to mechanical forces (Table 1).

Several enzymes within adhesion complexes appear to be MS. For example, mechanical forces applied to cells change both the localization and activity of FAK, a key non-receptor tyrosine kinase. Importantly, FAK signaling is necessary for cell behavioral responses to locally applied forces and changes in substratum rigidity (Wang et al., 2001). In growth cones, FAK is essential for point contact adhesion dynamics (assembly/disassembly) and axon guidance (Robles and Gomez, 2006; Woo et al., 2009; Myers and Gomez, 2011) and it is likely that mechanical properties of the environment influence FAK function. For example, FAK activation through deleted in colorectal cancer (DCC) requires both the immobilization of Netrin and acto-myosin contractility, suggesting that the kinase activity of FAK is mechanically dependent. Furthermore, inhibition of FAK during Netrin stimulation disrupts recruitment of adhesion complexes and traction force generation in growth cones (Moore et al., 2012). A second enzyme, receptor-like protein tyrosine phosphatase alpha (RPTP- $\alpha)$, is important for both sensing substratum stiffness and regulating axon extension. RPTP- $\alpha$ co-localizes with $\alpha \mathrm{v} \beta 6$ integrins where it regulates adhesion signaling by activating Src tyrosine kinases. Specifically on a rigid fibronectin substratum, RPTP- $\alpha$ promotes Src and Cas function and clustering to reinforce adhesion complexes and decrease axon outgrowth of hippocampal neurons (Kostic et al., 2007). However, whether RPTP- $\alpha$ senses substratum stiffness through a direct or indirect mechanism remains unclear.

Scaffolding proteins within adhesion complexes, such as p130Cas, talin, and filamin, also likely act as mechanosensors. Stretching of p130Cas exposes cryptic tyrosine residues that are phosphorylated by Src and Abl kinases and initiate several signaling cascades (Sawada et al., 2006). Loss of p130Cas function in developing neurons leads to aberrant axon pathfinding and dendrite patterning in vivo (Huang et al., 2007; Riccomagno et al., 2014). Recent evidence suggest that p130Cas may also be regulated by mechanically-dependent Netrin-DCC signaling during axon guidance (Moore et al., 2012). Similarly, stretching of talin leads to increased binding of the adapter vinculin to reinforce integrin-actin linkages (del Rio et al., 2009; Margadant et al., 2011). Talin has bifunctional roles in growth cones where it is important for the assembly of adhesions and as an integral scaffold within point contact adhesions (Sydor et al., 1996; Kerstein et al., 2013). Disruption of talin function leads to

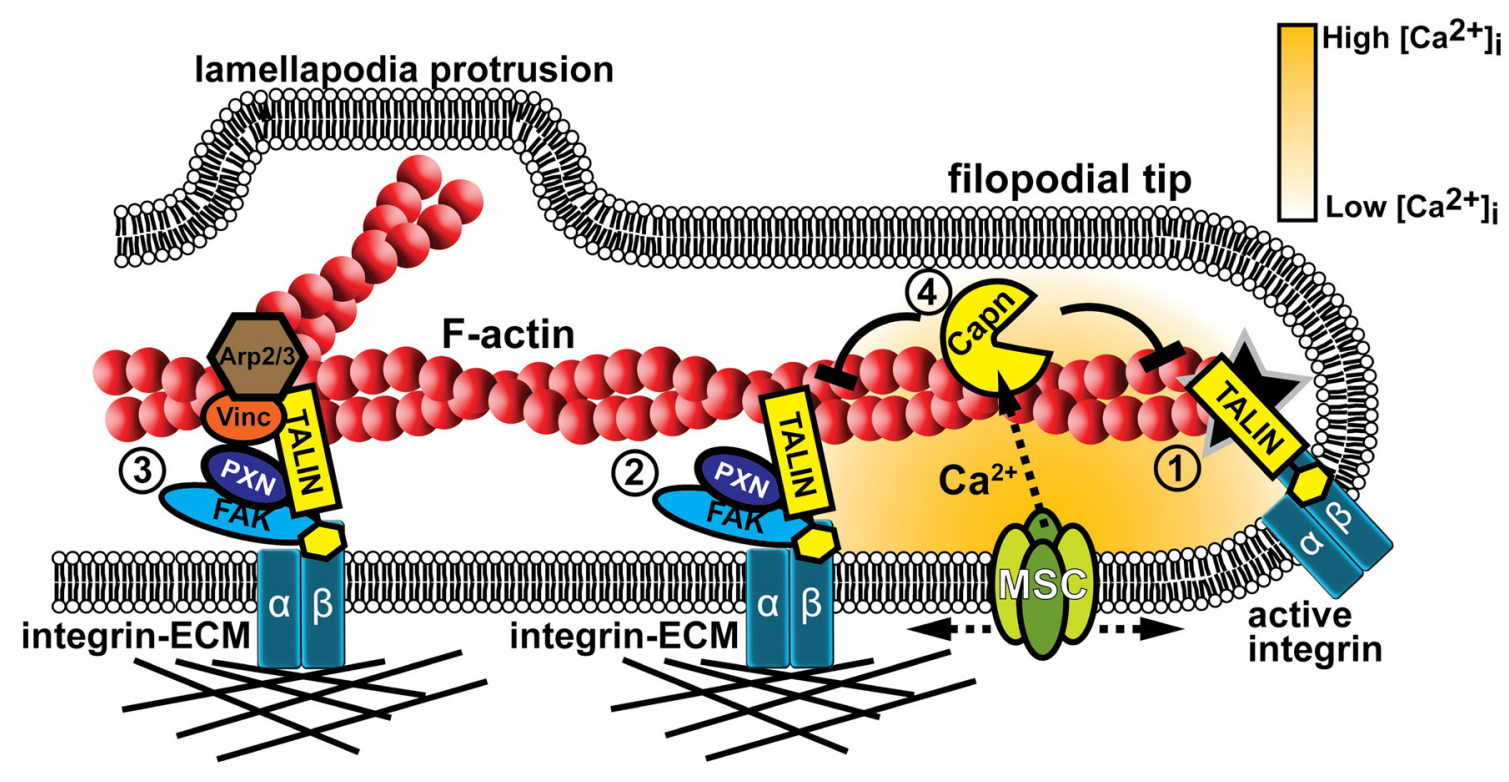

FIGURE 4 | Mechanotranduction within growth cone filopodia involves adhesion and $\mathbf{C a}^{2+}$ signaling. (1) Formation of point contact adhesions are initiated by talin-dependent inside-out activation of integrin receptors. (2) Point contact adhesions form when integrins bind to the ECM and intracellular proteins, such as FAK and paxillin, are recruited to signal and link integrins to the actin cytoskeleton. MS proteins, such as FAK, Talin, and CAS (not shown), are activated during substratum rigidity sensing and signaling for adhesion maturation. (3) Additional proteins are recruited during adhesion maturation, such as vinculin and the actin nucleator Arp2/3. Therefore, mature adhesions act as a signaling nexus for new actin filament polymerization off existing filaments, leading to veil protrusion. (4) Adhesion assembly and maturation can be disrupted when $\mathrm{Ca}^{2+}$ flows through MS channels (MSC). $\mathrm{Ca}^{2+}$ ions directly activate the protease calpain that targets specific adhesion proteins to inhibit or modulate their function (Kerstein et al., 2013). 
changes in filopodial dynamics and reduced growth cone motility (Sydor et al., 1996; Kerstein et al., 2013). In a similar fashion, filamins are scaffolding proteins that are stretched when bound between integrins and F-actin. Tension along filamin unveils cryptic binding sites for many signaling molecules such as RhoA, Rho-associated coiled-coil kinase (ROCK), p21-activated kinase (PAK), and PKC (Furuike et al., 2001; Razinia et al., 2012). In developing animals, mutations in filamins produce premature axon termination, ectopic branching, and aberrant pathfinding in vivo (Zheng et al., 2011; Nakamura et al., 2014).

A second set of mechanosensors in growth cones are MS ion channels (Table 1). MS channels have been most well studied in hair cells of the auditory system and the primary afferents of the somatosensory system (Geffeney and Goodman, 2012). However, these channels also have important roles in cell motility. MS channels regulate cell migration and growth cone motility through direct control of $\mathrm{Ca}^{2+}$ signaling (Lee et al., 1999; Jacques-Fricke et al., 2006; Franze et al., 2009; Wei et al., 2009; Kerstein et al., 2013). Evidence suggest that cellsubstratum interactions activate MS channels in motile cells since $\mathrm{Ca}^{2+}$ signals localize to adhesion clusters and in areas of high traction forces (Figure 4; Gomez et al., 2001; Doyle et al., 2004; Franze et al., 2009). In addition, substratum stiffness modulates $\mathrm{Ca}^{2+}$ influx as rigid substrata elicit a higher frequency of $\mathrm{Ca}^{2+}$ transients, which inhibits axon extension (Kim et al., 2009; Kerstein et al., 2013). Pharmacological inhibitors of MS channels have strong effects on growth cone motility. MS channel inhibitors such as, GsMTx4, $\mathrm{Gd}^{3+}$, Gentamicin all reduce the frequency of $\mathrm{Ca}^{2+}$ transients and accelerate axon extension (Jacques-Fricke et al., 2006; Kerstein et al., 2013). Furthermore, focal force applied to a growth cone induces collapse and retraction of the axon, which is blocked by inhibition of MS channels (Franze et al., 2009).

Recent reports suggest that growth cones express several types of MS ion channels, such as members of the Transient Receptor Potential (TRP) family. TRP channels form both homo- and heterotetrameric cation channels. Increasing evidence suggest an important role for TRP channels for environmental sensing from entire organisms to single cells. TRP channels transduce extracellular stimuli, like mechanical force, into biochemical signals through the influx of the second messenger $\mathrm{Ca}^{2+}(\mathrm{Wu}$ et al., 2010). Interestingly, several TRP channel subunits that are expressed in developing neurons are believed to be MS, therefore these MS channels may also be important for axon guidance. For example, TRPV2 can be activated by membrane stretch of developing neurons and expression of dominant negative TRPV2 in developing primary motor neurons inhibits axon extension in vivo (Shibasaki et al., 2010). However it is unclear how TRPV2 is mechanically activated in vivo. One possibility is that substratum rigidity modulates MS channel activity to regulate growth cone motility. Local filopodial $\mathrm{Ca}^{2+}$ transients appear to be generated by mechanical activation of transient receptor potential channel 1 (TRPC1), since these signals are reduced when rigidity of the substratum is decreased. In addition, the effects of MS channel blockers on axon outgrowth is lost with knockdown of TRPC1 and partially lost with knockdown of TRPV4 (Kerstein et al., 2013). Importantly, previous findings suggest that TRPC1 is an essential channel for axon pathfinding in vitro and in vivo (Shim et al., 2005; Wang and Poo, 2005; Wen et al., 2007). Other TRPC channels are also important during axon guidance and have been implicated in cellular mechanotransduction. TRPC5 is activated by hypo-osmotic stimulation and membrane stretch, and inhibited by the MS channel blocker GsMTx4 (Gomis et al., 2008). TRPC5 also plays a critical role in neurite initiation, axogensis, and axon extension (Greka et al., 2003; Hui et al., 2006; Wu et al., 2007; Davare et al., 2009). Similarly, TRPC6 is activated by membrane stretch and inhibited by GsMTx4 (Spassova et al., 2006) and is also important for axon growth and guidance in response to attractive guidance cues (Li et al., 2005). Recent evidence showed an important role for TRPM7 in the regulation on hippocampal axon extension in vitro (Turlova et al., 2014). In addition, TRPM7 was previously shown to respond to membrane stretch and fluid sheer force (Oancea et al., 2006; Wei et al., 2009). A major open question in the field is why are so many TRP channels mechanically sensitive. An intriguing new theory suggests that many TRP channels share a gating mechanism that relies on the local tension and shape of the plasma membrane (Liu and Montell, 2015). Furthermore each MS-TRP channel may be specific for a single neuron type. For example, the expression profiles of TRPC subfamily alone vary widely within the nervous system and exhibit even greater variation during development (Riccio et al., 2002; Strübing et al., 2003; Von Niederhäusern et al., 2013). One final possibility is that only a single TRP channel subunit is mechanically sensitive, but it may form tetrameric channels with many different TRP subunits depending on the cell type. This could result in many different channel tetramers being mechanically sensitive, with contribution from one subunit being sufficient to form a MS channel.

MS ion channels outside the TRP channel family may also be important. Piezo (Fam38a/b) ion channels were identified as MS channels in a siRNA based screen in the mechanically excitable Neuro2D cell line (Coste et al., 2010). Piezol controls cell migration in non-neuronal cells, possibly through regulating integrin binding activity (McHugh et al., 2010, 2012). However, Piezo1 is mainly expressed in non-neuronal cells, but Piezo2 is expressed neurons and is essential for the sense of touch in vertebrates (Faucherre et al., 2013; Ranade et al., 2014; Woo et al., 2014). Currently our understanding of Piezo2 is limited to adult animals, so future studies will need to address whether this MS channel has a role in neuronal development and growth cone motility.

How mechanical forces are transduced into MS channel gating is uncertain, but may involve coupling with the cytoskeleton (Clark et al., 2007; Hayakawa et al., 2008) interactions with lipids (Anishkin et al., 2014) and second messenger signals (Vriens et al., 2004; Alessandri-Haber et al., 2008). One intriguing site where local mechanical forces may regulate the opening of MS channels is at cell-cell contact sites or integrin adhesions with the ECM (Hayakawa et al., 2008; Kobayashi and Sokabe, 2010; Kazmierczak and Müller, 2012; Eisenhoffer and Rosenblatt, 2013). In support of this notion, both $\mathrm{Ca}^{2+}$ signals and TRP channels localize near integrin adhesion sites (Gomez et al., 2001; Matthews et al., 
2010; Kerstein et al., 2013). In neurons, these $\mathrm{Ca}^{2+}$ signals may act as a feedback mechanism on adhesion assembly and disassembly controlling growth cone motility (Robles et al., 2003; Kerstein et al., 2013). Interestingly, mechanical gating of MS channels likely depends on substratum rigidity and traction forces (Doyle et al., 2004; Munevar et al., 2004; Kerstein et al., 2013). This suggests that differences in the elastic environment of neurons may control their development in vivo through regulation of MS channel expression and function. In addition, MS channels may exert homeostatic regulation of the cytoskeleton and adhesion complexes through activation of downstream $\mathrm{Ca}^{2+}$ effectors. Previous studies have identified the $\mathrm{Ca}^{2+}$ effectors, calcineurin, CaMKII, and calpain as the main signaling pathways that regulate $\mathrm{Ca}^{2+}$ dependent growth cone motility and axon guidance (Robles et al., 2003; Wen et al., 2004). However the most intriguing example of mechanical feedback is the $\mathrm{Ca}^{2+}$-dependent protease calpain since it cleaves several adhesion and actin binding proteins to inhibit or modulate their function (Figure 4; Franco and Huttenlocher, 2005). Recent studies have shown that axon outgrowth and morphology are regulated through calpain specific cleavage of talin and cortactin, respectively (Mingorance-Le Meur and O'connor, 2009; Kerstein et al., 2013). However, additional calpain targets in growth cones are likely to exist. For example, in nonneuronal cells calpain cleaves the adhesion proteins Src, FAK, and Paxillin and the actin binding proteins Filamin and $\alpha$-actinin (reviewed in Franco and Huttenlocher, 2005; Chan et al., 2010; Cortesio et al., 2011). It is important to further elucidate the mechanism of feedback inhibition between MS channels and adhesion/cytoskeleton structures particularly in neuronal growth cones.

An interesting area where mechanotransduction has not been studied in growth cones is membrane trafficking. Endocytosis and exocytosis play an important role in growth cone navigation. For example, endocytosis of membrane and surface integrin receptors is required for repulsive growth turning from myelinassociated glycoprotein and semaphorin 3A (Hines et al., 2010; Tojima et al., 2010). Conversely, exocytosis is important for attractive axon turning and increased axon branching (Tojima et al., 2007, 2014; Winkle et al., 2014). Endocytosis and exocytosis may also directly influence mechanical signals. Recent studies showed that during cell migration leading edge protrusions increase plasma membrane tension, which activates further exocytosis to relieve increased tension (Gauthier et al., 2011). However, the mechanism of sensing membrane tension remains unknown. One possibility is that membrane tension activates MS ion channels. Consistent with this, hypotonic solutions induce cell swelling and increase membrane tension, which activates $\mathrm{Ca}^{2+}$ influx through MS channels in growth cones (JacquesFricke et al., 2006; Kerstein et al., 2013). Another possibility is that membrane tension is required for the localization of leading edge signaling proteins such as the GTPase Racl and the SCAR/WAVE complex, as shown recently in neutrophils (Houk et al., 2012). Unfortunately, our understanding of the relationship membrane tension and trafficking is limited in neuronal growth cones and a considerable amount of work remains before a mechanism is completely understood.

\section{Mechanical Properties of the Environment Regulate Cell Migration and Axon Growth}

Pioneering studies on the mechanisms of growth cone guidance performed both in vitro and in vivo focused on the role of cell adhesion as a principal determinant of pathfinding (Gomez et al., 1996; Woo and Gomez, 2006; Bard et al., 2008; Bechara et al., 2008; Myers et al., 2011). Using patterned substrata of differential adhesivity, investigators showed that growth cones could be directed in vitro simply by differences in adhesion (Hammarback et al., 1985; Gomez and Letourneau, 1994). These early experiments implied that axons may be targeted in vivo by adhesive interactions with extracellular ligands. A number of different cell recognition molecules on the surface of growth cones are known to have adhesive properties (Rutishauser, 1985; Lagenaur and Lemmon, 1987; Schmidt et al., 1995), which function to stabilize leading edge protrusions. While it is still uncertain the relative contributions of adhesion vs. biochemical signaling in the control of axon pathfinding in vivo, it is likely that differential cell adhesion has some influence (Caudy and Bentley, 1986a,b; O'Connor et al., 1990).

In addition to the classical ECM components, axon guidance cues are immobilized in the extracellular environment to some extent. While this includes large ECM proteins and cell surface adhesion molecules, small secreted growth factors and chemokines are also likely immobilized. Growing evidence suggests that growth factors bind with high specificity to fibronectin type III repeats and heparin sulfate glycosaminoglycans contained within many ECM proteins such as fibronectin, tenascin, and laminin (Hynes, 2002, 2009). Growth factor binding to the ECM likely serves to localize or concentrate soluble factors [e.g., fibroblast growth factor (FGF), Wnt, bone morphogenic proteins (BMPs)] near the cell binding sites and help establish stable gradients necessary for pattern formation in vivo. In some cases, growth factor receptors may cooperate with cell adhesion receptors (e.g., integrin) for cell binding, as has been demonstrated for a5ß1 and vascular endothelial growth factor (VEGF) receptor (Rahman et al., 2005). Secreted axon guidance cues have also been demonstrated to bind ECM proteins suggesting that immobilized guidance factors serve as adhesive ligands or provide mechanical support in association with ECM. For example, the repellant Slit must bind collagen for proper lamination of the zebrafish optic tectum (Xiao et al., 2011). Other secreted axon guidance cues such as netrins, BMPs and Sema3s bind the ECM and induce mechanical signals ( $\mathrm{Hu}, 2001$; Manitt and Kennedy, 2002; De Wit et al., 2005; Moore et al., 2012). To provide an additional level of control, local proteolysis of ECM may serve to release growth factors in a spatially and temporally controlled manner. Growth cones have recently been shown to target matrix metalloproteases using invadosomes (SantiagoMedina et al., 2015). Therefore, while bath application or local gradients of soluble guidance cues has been the prevailing method for studying axon guidance behaviors in vitro, the role of mechanical signaling by immobilized ligands in three dimensional environments is an important and often overlooked 
consideration for our full understanding of the mechanisms of neural network formation.

Growth cones in vitro have been shown to generate tension on neighboring cells and the underlying matrix (Lamoureux et al., 1989; Balgude et al., 2001; Moore et al., 2010; Moore and Sheetz, 2011). Many axon guidance cues are immobilized in the extracellular environment to some extent (as described above), therefore mechanical tensile forces likely contribute to many attractive and repulsive (release of adhesion) guidance behaviors. Recent evidence suggest that even under classic chemical gradient turning assays, mechanotransduction is necessary for chemoattraction. For example, chemical gradients of netrin-1 generated in vitro only promote growth cone turning when netrin can bind to the substratum (Moore et al., 2009). Here growth cones utilize netrin as an adhesive ligand that supports traction forces that exceed $60 \mathrm{pN}$ (Moore et al., 2009). Inhibition of netrin substrata adsorption, via co-treatment with heparin, inhibited axon outgrowth (Moore et al., 2012). Interestingly, commissural interneurons in vivo will turn towards ectopically secreted full length netrin, but are not guided towards truncated netrin lacking the domains required for substratum adsorption (Moore et al., 2012). Further, guidance toward Netrin depends upon FAK activity, a MS kinase, and myosin-II motor-induced traction forces. Other "soluble" axon guidance cues may require immobilization to elicit their guidance effects on extending axons. For example, ephrinA5 appears to produce repulsive turning or collapse in both border turning assays or as a soluble ligand, but the ability of "soluble" ephrinA5 to bind was not tested in this study (Weinl et al., 2003). EphrinA repellants may disrupt growth cone adhesion to the ECM or to neighboring cells by preventing point contact formation (Woo et al., 2009), or by activating metalloprotease-mediated cleavage of cell surface ephrinA ligands (Hattori et al., 2000), respectively.

While immobilized ligands clearly support traction forces generated by cells and growth cones, many recent studies show that substratum elasticity, or stiffness, also influences the development of neurons (Tyler, 2012; Franze, 2013). Cells and neurons have a remarkable ability to adapt to their mechanical environment. While most cells minimally require anchorage to a solid substratum and do not fully differentiate in liquid suspension, the elasticity of the supporting adhesive substratum can vary over a wide range. Neurons are particularly adaptable cells, as they will morphologically differentiate on extremely soft substrata and tissues, such as brain [Young's modulus $=\sim 100-1000$ Pascal $(\mathrm{Pa})]$, as well as on extremely rigid environments, such as ECM-coated glass and bone (>10 gPa, 20 $\mathrm{mPa}$, respectively), covering an impressive $>10,000$ fold range of elasticities (Kruse et al., 2008; Tyler, 2012). Importantly, the elastic modulus (rigidity) of the cell substratum can strongly influence cell differentiation, morphology, motility, and survival (Geiger et al., 2001, 2009; Moore and Sheetz, 2011; Musah et al., 2014). Understanding the roles of substratum elasticity on neuronal development is critical since developing axons and dendrites will encounter widely varying elastic environments during pathfinding to their targets.

Numerous studies over the past decade have shown that growth cone motility depends on the compliance of the cell substratum (Tyler, 2012; Franze, 2013). This is a cell migration process known as durotaxis. Previous studies used a variety of materials to generate variable elastic cell culture conditions to study neuronal durotaxis, including polyacrylamide (PAA; Flanagan et al., 2002; Georges et al., 2006; Kostic et al., 2007; Jiang et al., 2008; Koch et al., 2012) and polydimethylsiloxane (PDMS) in 2D (von Philipsborn et al., 2006; Cheng et al., 2011; Kerstein et al., 2013), as well as collagen I gels (Willits and Skornia, 2004; Sundararaghavan et al., 2009) and agarose hydrogels for 3D conditions (Hammarback and Letourneau, 1986; Balgude et al., 2001; Mai et al., 2009). Here we compare results across these conditions (Table 2), but it is important to note that many variables beyond substratum compliance may contribute to observed differences. For example, non-biological materials typically must be conditioned with a biological ligand to support axon extension. A range of ECM proteins at varying concentrations or serum have been used to promote axon outgrowth. In addition to the variable biological conditions tested, the methods used to measure the elastic moduli of the cell substrata also varies. Therefore, Young's modulus values determined by atomic force microscopy (AFM) may differ from those measured by sheer stress rheometry or micro-position displacement devices. These caveats should be considered whenever comparing between different studies.

One of the first studies to examine neurite outgrowth under different elastic conditions cultured dorsal root ganglia (DRG) neurons within varying concentrations of agarose gels in the presence of $10 \%$ fetal bovine serum (FBS). This study found that axons extend more rapidly within softer gels $(<20 \mathrm{~Pa})$ and that the rate of outgrowth plateaus above $60 \mathrm{~Pa}$ (Balgude et al., 2001). More recently, PAA gels were used to test the effects of substratum elasticity on DRG axon outgrowth. By examining neurite lengths from fixed DRG neurons plated on PAA coated with laminin, Jeff Urbach and colleagues found that axon outgrowth peaks on $1000 \mathrm{~Pa}$ gels and decreases on PAA gels below and above this optimal elasticity (Koch et al., 2012). Interestingly, under the same conditions, this group found that hippocampal neurons exhibit no preference for soft substrata, suggesting this behavior may be selective for peripheral neurons. However, this result is contradictory to a previous report that found that hippocampal axons preferred soft conditions $(500 \mathrm{~Pa})$ over more rigid (4 KPa; Kostic et al., 2007). It is important to note that the latter study differed from the former as they used PAA gels coated with fibronectin rather than laminin. Other studies using different types of neurons and culture conditions, including within collagen gels, have found preferential outgrowth on softer substrata (Table 2, Balgude et al., 2001; Flanagan et al., 2002; Willits and Skornia, 2004; Georges et al., 2006; Jiang et al., 2008; Kerstein et al., 2013), but it will be important to standardize experimental conditions and elastic modulus measurements to make general statements regarding the effects of the mechanical environment on outgrowth. In addition to effects on axon outgrowth, other studies have shown that softer substrata promote neurite branching of several neuronal types (Wang et al., 2001; Flanagan et al., 2002; Georges et al., 2006; von Philipsborn et al., 2006). 
TABLE 1 | Mechanosensitive (MS) proteins in growth cones.

\begin{tabular}{|c|c|c|c|c|}
\hline Gene name & $\begin{array}{l}\text { Mechanical } \\
\text { activation }\end{array}$ & $\begin{array}{l}\text { Downstream } \\
\text { signaling }\end{array}$ & $\begin{array}{l}\text { Growth cone } \\
\text { mechanism }\end{array}$ & $\begin{array}{l}\text { Key references } \\
\text { (Bold-Mechano. } \\
\text { Italics-Growth cone) }\end{array}$ \\
\hline FAK & Increased kinase activity & $\begin{array}{l}\text { - Tyrosine phosphorylation } \\
\text { - Regulation of adhesion } \\
\text { dynamics }\end{array}$ & $\begin{array}{l}\text { - Required for attractive } \\
\text { axon turning } \\
\text { - Promotes axon outgrowth }\end{array}$ & $\begin{array}{l}\text { Robles and Gomez (2006) } \\
\text { Myers et al. (2011) } \\
\text { Moore et al. (2012) }\end{array}$ \\
\hline p130Cas & $\begin{array}{l}\text { Increased availability of } \\
\text { tyrosine residues }\end{array}$ & $\begin{array}{l}\text { - Phosphorylated by } \\
\text { Src and Abl kinases }\end{array}$ & $\begin{array}{l}\text { - Required for in vivo and in vitro } \\
\text { axon pathfinding and } \\
\text { dendritic patterning. }\end{array}$ & $\begin{array}{l}\text { Sawada et al. (2006) } \\
\text { Huang et al., } 2007 \\
\text { Riccomagno et al. (2014) }\end{array}$ \\
\hline Talin & $\begin{array}{l}\text { Increased availability of } \\
\text { vinculin binding sites }\end{array}$ & $\begin{array}{l}\text { - Vinculin binding } \\
\text { - Reinforcement of integrin } \\
\text {-actin linkages }\end{array}$ & $\begin{array}{l}\text { - Required for } \\
\text { filopodia and growth } \\
\text { cone motility. }\end{array}$ & $\begin{array}{l}\text { del Rio et al. (2009) } \\
\text { Margadant et al. (2011) } \\
\text { Kerstein et al. (2013) } \\
\text { Sydor et al. (1996) }\end{array}$ \\
\hline \multicolumn{5}{|l|}{ Ion channels } \\
\hline TRPC1 & $\begin{array}{l}\text { Channel opening } \\
\text { (membrane-stretch/ } \\
\text { integrin transduction) }\end{array}$ & $\begin{array}{l}\text { - } \mathrm{Ca}^{2+} \text { influx } \\
\text { - Activation of calpain } \\
\text { - Activation of calcineurin }\end{array}$ & $\begin{array}{l}\text { - Inhibition of axon } \\
\text { outgrowth } \\
\text { - Required for attractive/ } \\
\text { repulsive axon turning }\end{array}$ & $\begin{array}{l}\text { Maroto et al. (2005) } \\
\text { Wang and Poo (2005) } \\
\text { Shim et al. (2005) } \\
\text { Wen et al. (2007) } \\
\text { Kerstein et al. (2013) }\end{array}$ \\
\hline TRPC5 & $\begin{array}{l}\text { Channel opening } \\
\text { (membrane-stretch) }\end{array}$ & - $\mathrm{Ca}^{2+}$ influx & - Inhibits axon outgrowth & $\begin{array}{l}\text { Greka et al. (2003) } \\
\text { Gomis et al. (2008) }\end{array}$ \\
\hline TRPC6 & $\begin{array}{l}\text { Channel opening } \\
\text { (membrane-stretch) }\end{array}$ & - $\mathrm{Ca}^{2+}$ influx & $\begin{array}{l}\text { - Promotes axon outgrowth } \\
\text { - Attractive axon turning }\end{array}$ & $\begin{array}{l}\text { Li et al. (2005) } \\
\text { Spassova et al. (2006) }\end{array}$ \\
\hline Piezo2 & $\begin{array}{l}\text { Channel opening } \\
\text { (membrane-stretch) }\end{array}$ & - $\mathrm{Ca}^{2+}$ influx & - Unknown & Coste et al. (2010) \\
\hline
\end{tabular}

\section{Mechanical Environment Influences Cell Migration and Axon Growth In vivo}

Growth cone navigation may be influenced by surrounding physical barriers causing them to grow around or in between different tissue structures. For example, when a severed motor neuron axon begins to regenerate it typically will extend, branch, and synapse in the same location as the pioneer axon. Regenerating axons are physically constrained to the tubes that Schwann cells formed around the original axon (Nguyen et al., 2002). Interestingly, peripheral axon regeneration declines with age, not because the axons lose their intrinsic outgrowth capabilities, but due to the lack of clearance of glial and nerve debris that impose physical barriers to the regenerating axons (Kang and Lichtman, 2013). In the central nervous system
(CNS), similar regeneration limitations have been observed when immature neurons were transplanted into rats with striatal lesions (Isacson et al., 1995). In addition to regenerating axons, physical interactions are important during development as well. For example, zebrafish lateral line axons extend with the collective migration of lateral line primordial cells through a physical, but not chemical, interaction. The authors described this as a "tugging" action on the axons by the migrating lateral line primordia (Gilmour et al., 2004). Furthermore, zebrafish Rohan-Beard peripheral axons normally project ventrally, however when the contractions of the underlying muscle tissue are prevented, genetically or pharmacologically, these axons project more longitudinally (Paulus et al., 2009). In Zebrafish diwanka mutants, MN growth cones fail to exit the spinal cord into the periphery (Granato et al., 1996; Zeller and Granato, 
TABLE 2 | The effects of substrate rigidity on neurite outgrowth and morphology.

\begin{tabular}{|c|c|c|c|c|}
\hline Neuron type & Substrate (ECM) & $\begin{array}{l}\text { Elasticity range } \\
\text { (Modulus) }\end{array}$ & Neurite phenotype & Reference \\
\hline E9 Chick DRG & 3D Agarose (None) & $0.003-0.130$ kPa* (Shear) & $\begin{array}{l}\text { Increased length on soft } \\
\text { substrates }\end{array}$ & Balgude et al. (2001) \\
\hline E9 Chick DRG & $\begin{array}{l}\text { 3D Collagen I Gel } \\
\text { (varied collegan conc.) }\end{array}$ & $0.002-0.017$ kPa (Shear) & $\begin{array}{l}\text { Increased length on soft } \\
\text { substrates }\end{array}$ & Willits and Skornia (2004) \\
\hline E8 Chick DRG & $\begin{array}{l}\text { 3D Collagen I Gel (varied } \\
\text { genipin crosslinking) }\end{array}$ & $0.05-0.80$ kPa (Shear) & $\begin{array}{l}\text { Increased length on soft } \\
\text { substrates }\end{array}$ & Sundararaghavan et al. (2009) \\
\hline E13.5 Mouse Spinal Cord & PAA (Matrigel) & $0.050-0.550$ kPa* (Shear) & $\begin{array}{l}\text { Increased branching on } \\
\text { soft substrates }\end{array}$ & Flanagan et al. (2002) \\
\hline PO Mouse Hippocampal & PAA (Fibronectin or Laminin) & 0.5-7.5 kPa (Young's) & $\begin{array}{l}\text { Increased length on } \\
\text { soft substrates }\end{array}$ & Kostic et al. (2007) \\
\hline PO Rat DRG & PAA (Laminin) & 0.150-5.0 kPa (Young's) & $\begin{array}{l}\text { Maximum length on } 1.0 \mathrm{kPa} \\
\text { substratum. }\end{array}$ & Koch et al. (2012) \\
\hline Adult Mouse DRG & PDMS (Poly-L-Lysine) & 18-1882 kPa (Young's) & $\begin{array}{l}\text { Maximum length on } 88 \mathrm{kPa} \\
\text { substratum }\end{array}$ & Cheng et al. (2011) \\
\hline Stage 22 Xenopus spinal cord & PDMS (Fibronectin) & 950-1800 kPa (Young's) & $\begin{array}{l}\text { Increased outgrowth } \\
\text { on soft substrates }\end{array}$ & Kerstein et al. (2013) \\
\hline E8-9 Chick DRG & $\begin{array}{l}\text { Silk Fibroin Hydrogel } \\
\text { (Fibronectin or Laminin) }\end{array}$ & 4-33 kPa (Young's) & $\begin{array}{l}\text { Maximum length on } 7-22 \mathrm{kPa} \\
\text { substrates }\end{array}$ & Hopkins et al. (2013) \\
\hline
\end{tabular}

Abbreviations: $\mathrm{kPa}$, kiloPascals; PAA, polyacrylamide; PDMS, Polydimethylsiloxane. ${ }^{*} \mathrm{kPa}$ were converted from $\mathrm{kdynes} / \mathrm{cm}^{2}$.

1999; Schneider and Granato, 2006). diwanka mutations were found to be in a lysyl hydroxylase protein (LH3), an enzyme with glycosyltransferase activity that modifies type XVIII collagen. Interestingly, the glycosyltransferase activity of LH3 functions within adaxial cells to chemically modify collagen XVIII that is deposited on the surface of the developing myotome. In this model, collagen XVIII is glycosylated by LH3 and secreted into the ECM where it becomes a suitable substratum to promote the exit of motor axons into the periphery. While it is unclear what the precise roles of collagen glycosylation are toward developing axons, there is evidence it can regulate fibrillogenesis, crosslinking, remodeling and collagen-cell interactions, all of which likely influence mechanical signaling (Yamauchi and Sricholpech, 2012). Glycosylation of dystroglycan also regulates axon guidance at the floor plate of the developing mouse spinal cord and is required for binding and localizing Slit to the floor plate (Wright et al., 2012). However, it is unknown whether the immobilization of Slit is required full receptor activation, as it is for the ligand Netrin (described above). It will be important in the future to determine which immobilized axon guidance cues, such as ECM, cell adhesion molecules and growth factors, use mechanical signaling to elicit their effects on growth cones.

\section{Axons Extend Through a Mechanically Diverse Environments In vivo}

The elasticity of the extracellular environment in vivo varies across tissues, with age and under pathological conditions. For example, in breast cancer tissues, mammary carcinoma cell migration is influenced by the physical properties of the collagen matrix, such as fiber alignment, density, and stiffness (reviewed in Schedin and Keely, 2011). Interestingly, increases in density and stiffness of the ECM within breast tissue and mammary gland tumors are the key risk factors for the development of breast cancer and the metastatic potential of cancer cells (Boyd et al., 1998; Paszek et al., 2005; Provenzano et al., 2009). These findings under pathological conditions suggest that normal cell migration and the extension of neuronal processes, may also be influenced by local differences in the mechanical environment in vivo. The environment of elongating axons and dendrites, which can traverse great distances, varies widely in substratum elasticity (Young's Modulus) from flexible neural tissues to highly rigid skin, muscle and bone suggesting a role for growth cone durotaxis in vivo. (Discher et al., 2005, 2009). Furthermore, local variations in substratum elasticity have been observed within the CNS. AFM measurements made from dissociated hippocampal and retinal neurons found that individual neurons were more rigid than glial cells ( $\mathrm{Lu}$ et al., 2006). Therefore, the extension of axons and dendrites along different cell types may be influenced by the intrinsic mechanical properties of the cells. In addition, regional differences in tissue elasticities have been observed across specific regions of the CNS. Scanning force micrographs of rat cerebellar slices showed that gray matter is more elastic than white matter (Christ et al., 2010). In addition, slices from developing mouse cerebral cortex show variations in tissue elasticity in both a spatial and temporal manner, suggesting a mechanical niche may influence cellular differentiation, migration, and morphology in vivo (Iwashita et al., 2014). 
Substratum elasticity in vivo is determined by composition, density and orientation of different ECM components. For example, recent work has shown that cross-linking of collagen fibers by lysyl oxidase (Lox) in the drosophila eye disc controls the stiffness of the tissue. Further, disruption of Lox leads to ectopic migration of glial cells suggesting tissue stiffness defines specific migration patterns (Kim et al., 2014). In addition, Lox knockdown or overexpression in the mouse cerebellum modulates Purkinje neuron dendritic development, where increased Lox activity may inhibit outgrowth through increasing collagen cross-linking and substratum stiffness ( $\mathrm{Li}$ et al., 2010). Recent studies have provided evidence to support a role for substratum stiffness in guiding developing axons in vivo, but future studies will need to clarify how and when axon growth is specifically modulated by substratum elasticity. In addition, the study of mechanosignaling during axon guidance requires the development of a robust and reliable in vivo model of growth cone durotaxis.

\section{Future Prospectives and Challenges to the Field}

There are many outstanding questions regarding the roles of mechanical forces in the regulation of growth cone motility and axon guidance. Within cells and growth cones, it is unclear which proteins function as mechanosensors and how molecular forces are transferred onto target proteins. In particular, it is not clear how MS ion channels are gated at the plasma membrane and the molecular targets of calcium signals. Ion channel gating may occur at point contact adhesions, where myosin II contractile forces are focused at integrin-ECM contacts (Gomez et al., 2001; Hayakawa et al., 2008; Matthews et al., 2010). Importantly, it is likely that specific calcium influx and release pathways control distinct downstream targets that can have opposing effects on motility (Gomez and Zheng, 2006). However, since many MS ion channels are activated by multiple stimuli, manipulating mechanically activated currents specifically is challenging. For example, TRPC1 subunits are known to assemble into channels that are activated by both mechanical and chemical signals ( $\mathrm{Wu}$ et al., 2010). Another major challenge to our understanding of mechanical signaling, is the composition and regulation of ECM adhesions. This is particularly difficult in growth cones, as point contact adhesions are smaller and more dynamic than focal adhesions found in non-neuronal cells. Proteomic based approaches are being attempted for focal adhesions, but are

\section{References}

Alessandri-Haber, N., Dina, O. A., Joseph, E. K., Reichling, D. B., and Levine, J. D. (2008). Interaction of transient receptor potential vanilloid 4, integrin and SRC tyrosine kinase in mechanical hyperalgesia. J. Neurosci. 28, 1046-1057. doi: 10. 1523/JNEUROSCI.4497-07.2008

Anishkin, A., Loukin, S. H., Teng, J., and Kung, C. (2014). Feeling the hidden mechanical forces in lipid bilayer is an original sense. Proc. Natl. Acad. Sci. US A 111, 7898-7905. doi: 10.1073/pnas.1313364111

Balgude, A. P., Yu, X., Szymanski, A., and Bellamkonda, R. V. (2001). Agarose gel stiffness determines rate of DRG neurite extension in $3 \mathrm{D}$ cultures. Biomaterials 22, 1077-1084. doi: 10.1016/s0142-9612(00)00350-1 hampered by sample heterogeneity (Kuo et al., 2012; Humphries et al., 2015). Point contact adhesions will certainly also be highly heterogenous within growth cones and their composition is regulated by cross talk from guidance cue receptors to control mechanical forces (Myers et al., 2011; Gomez and Letourneau, 2014). In addition, point contact adhesions have not been observed in vivo, where they will clearly differ depending on substratum association. During axon pathfinding to distal targets, growth cones will bind many different adhesive substrata, ranging from ECM proteins to cell adhesion molecules on neighboring neurons and glia. It is important to both visualize and manipulate point contact adhesions in vivo to test their roles in axon guidance.

Determining the roles of tissue elasticity and mechanical signaling is particularly difficult in vivo. While it is clear that growth cones must migrate across widely varying elastic microenvironments en route to their proper synaptic targets, it is not known whether changes in tissue elasticity influences growth cone morphology or motility. For example, motoneuron axons begin in the soft CNS, but exit by penetrating the surrounding basal lamina (Santiago-Medina et al., 2015) to enter the sclerotome, which they preferentially cross within the rostral half (Keynes and Stern, 1984). After entering the periphery, $\mathrm{MN}$ axons are sorted toward targets in the body wall and limb muscles (Bonanomi and Pfaff, 2010), which are significantly more rigid tissues(Engler et al., 2004; Discher et al., 2009). Distinguishing specific effects of the mechanical environment vs. chemical signals is difficult in vivo. However, progress has been made by examining the effects of mutations in ECM cross linking enzymes that regulate the mechanical, but not the chemical composition of the environment (Kim et al., 2014). Additional functional studies should test the effects on axon guidance of manipulations that both increase and decrease tissue elasticity. Moreover, these functional studies can be coupled with direction measurements of elastic modulus within tissues in vivo using AFM (Franze, 2011).

\section{Acknowledgments}

The authors would like to thank the members of the Gomez lab for helpful comments on this manuscript. This work was supported by NIH R56NS041564 and R21NS088477 to TMG, NIH F31NS074732 to PCK and NIH T32GM007507 to the Neuroscience Training Program.

Bamburg, J. R. (1999). Proteins of the ADF/cofilin family: essential regulators of actin dynamics. Annu. Rev. Cell Dev. Biol. 15, 185-230. doi: 10.1146/annurev. cellbio.15.1.185

Bard, L., Boscher, C., Lambert, M., Mège, R. M., Choquet, D., and Thoumine, O. (2008). A molecular clutch between the actin flow and N-cadherin adhesions drives growth cone migration. J. Neurosci. 28, 5879-5890. doi: 10.1523/JNEUROSCI.5331-07. 2008

Bechara, A., Nawabi, H., Moret, F., Yaron, A., Weaver, E., Bozon, M., et al. (2008). FAK-MAPK-dependent adhesion disassembly downstream of L1 contributes to semaphorin3A-induced collapse. EMBO J. 27, 1549-1562. doi: $10.1038 /$ emboj.2008.86 
Berg, J. S., and Cheney, R. E. (2002). Myosin-X is an unconventional myosin that undergoes intrafilopodial motility. Nat. Cell Biol. 4, 246-250. doi: 10. $1038 /$ ncb762

Bonanomi, D., and Pfaff, S. L. (2010). Motor axon pathfinding. Cold Spring Harb. Perspect. Biol. 2:a001735. doi: 10.1101/cshperspect.a001735

Bornschlögl, T. (2013). How filopodia pull: what we know about the mechanics and dynamics of filopodia. Cytoskeleton (Hoboken) 70, 590-603. doi: 10. $1002 / \mathrm{cm} .21130$

Boyd, N. F., Lockwood, G. A., Byng, J. W., Tritchler, D. L., and Yaffe, M. J. (1998). Mammographic densities and breast cancer risk. Cancer Epidemiol. Biomarkers Prev. 7, 1133-1144.

Brown, M. E., and Bridgman, P. C. (2003). Retrograde flow rate is increased in growth cones from myosin IIB knockout mice. J. Cell Sci. 116, 1087-1094. doi: $10.1242 /$ jcs. 00335

Carlier, M. F., and Pantaloni, D. (2007). Control of actin assembly dynamics in cell motility. J. Biol. Chem. 282, 23005-23009. doi: 10.1074/jbc.r700020200

Caudy, M., and Bentley, D. (1986a). Pioneer growth cone morphologies reveal proximal increases in substrate affinity within leg segments of grasshopper embryos. J. Neurosci. 6, 364-379.

Caudy, M., and Bentley, D. (1986b). Pioneer growth cone steering along a series of neuronal and non-neuronal cues of different affinities. J. Neurosci. 6, 1781-1795.

Chan, K. T., Bennin, D. A., and Huttenlocher, A. (2010). Regulation of adhesion dynamics by calpain-mediated proteolysis of focal adhesion kinase (FAK). J. Biol. Chem. 285, 11418-11426. doi: 10.1074/jbc.M109.090746

Chan, C. E., and Odde, D. J. (2008). Traction dynamics of filopodia on compliant substrates. Science 322, 1687-1691. doi: 10.1126/science.1163595

Chèdotal, A., and Richards, L. J. (2010). Wiring the brain: the biology of neuronal guidance. Cold Spring Harb. Perspect. Biol. 2:a001917. doi: 10.1101/cshperspect. a001917

Cheng, C. M., LeDuc, P. R., and Lin, Y. W. (2011). Localized bimodal response of neurite extensions and structural proteins in dorsal-root ganglion neurons with controlled polydimethylsiloxane substrate stiffness. J. Biomech. 44, 856-862. doi: 10.1016/j.jbiomech.2010.12.006

Christ, A. F., Franze, K., Gautier, H., Moshayedi, P., Fawcett, J., Franklin, R. J., et al. (2010). Mechanical difference between white and gray matter in the rat cerebellum measured by scanning force microscopy. J. Biomech. 43, 2986-2992. doi: 10.1016/j.jbiomech.2010.07.002

Clark, K., Langeslag, M., Figdor, C. G., and van Leeuwen, F. N. (2007). Myosin II and mechanotransduction: a balancing act. Trends Cell Biol. 17, 178-186. doi: 10.1016/j.tcb.2007.02.002

Cluzel, C., Saltel, F., Lussi, J., Paulhe, F., Imhof, B. A., and Wehrle-Haller, B. (2005). The mechanisms and dynamics of (alpha)v(beta) 3 integrin clustering in living cells. J. Cell Biol. 171, 383-392. doi: 10.1083/jcb.200503017

Cortesio, C. L., Boateng, L. R., Piazza, T. M., Bennin, D. A., and Huttenlocher, A. (2011). Calpain-mediated proteolysis of paxillin negatively regulates focal adhesion dynamics and cell migration. J. Biol. Chem. 286, 9998-10006. doi: 10. 1074/jbc.M110.187294

Coste, B., Mathur, J., Schmidt, M., Earley, T. J., Ranade, S., Petrus, M. J., et al. (2010). Piezo1 and Piezo2 are essential components of distinct mechanically activated cation channels. Science 330, 55-60. doi: 10.1126/science. 1193270

Davare, M. A., Fortin, D. A., Saneyoshi, T., Nygaard, S., Kaech, S., Banker, G., et al. (2009). Transient receptor potential canonical 5 channels activate $\mathrm{Ca} 2+/$ calmodulin kinase Igamma to promote axon formation in hippocampal neurons. J. Neurosci. 29, 9794-9808. doi: 10.1523/JNEUROSCI.1544-09.2009

De Wit, J., De Winter, F., Klooster, J., and Verhaagen, J. (2005). Semaphorin 3A displays a punctate distribution on the surface of neuronal cells and interacts with proteoglycans in the extracellular matrix. Mol. Cell. Neurosci. 29, 40-55. doi: 10.1016/j.mcn.2004.12.009

Dent, E. W., Gupton, S. L., and Gertler, F. B. (2011). The growth cone cytoskeleton in axon outgrowth and guidance. Cold Spring Harb. Perspect. Biol. 3:a001800. doi: 10.1101/cshperspect.a001800

del Rio, A., Perez-Jimenez, R., Liu, R., Roca-Cusachs, P., Fernandez, J. M., and Sheetz, M. P. (2009). Stretching single talin rod molecules activates vinculin binding. Science 323, 638-641. doi: 10.1126/science.1162912

Discher, D. E., Janmey, P., and Wang, Y. L. (2005). Tissue cells feel and respond to the stiffness of their substrate. Science 310, 1139-1143. doi: 10.1126/science. 1116995
Discher, D. E., Mooney, D. J., and Zandstra, P. W. (2009). Growth factors, matrices and forces combine and control stem cells. Science 324, 1673-1677. doi: 10. $1126 /$ science. 1171643

Doyle, A., Marganski, W., and Lee, J. (2004). Calcium transients induce spatially coordinated increases in traction force during the movement of fish keratocytes. J. Cell Sci. 117, 2203-2214. doi: 10.1242/jcs.01087

Du, X., Gu, M., Weisel, J. W., Nagaswami, C., Bennett, J. S., Bowditch, R., et al. (1993). Long range propagation of conformational changes in integrin alpha IIb beta 3. J. Biol. Chem. 268, 23087-23092.

Dudanova, I., and Klein, R. (2013). Integration of guidance cues: parallel signaling and crosstalk. Trends Neurosci. 36, 295-304. doi: 10.1016/j.tins.2013.01.007

Eisenhoffer, G. T., and Rosenblatt, J. (2013). Bringing balance by force: live cell extrusion controls epithelial cell numbers. Trends Cell Biol. 23, 185-192. doi: 10. 1016/j.tcb.2012.11.006

Engler, A. J., Griffin, M. A., Sen, S., Bönnemann, C. G., Sweeney, H. L., and Discher, D. E. (2004). Myotubes differentiate optimally on substrates with tissue-like stiffness: pathological implications for soft or stiff microenvironments. J. Cell Biol. 166, 877-887. doi: 10.1083/jcb.200405004

Faucherre, A., Nargeot, J., Mangoni, M. E., and Jopling, C. (2013). piezo2b regulates vertebrate light touch response. J. Neurosci. 33, 17089-17094. doi: 10. 1523/JNEUROSCI.0522-13.2013

Flanagan, L. A., Ju, Y. E., Marg, B., Osterfield, M., and Janmey, P. A. (2002). Neurite branching on deformable substrates. Neuroreport 13, 2411-2415. doi: 10.1097/00001756-200212200-00007

Forscher, P., and Smith, S. J. (1988). Actions of cytochalasins on the organization of actin filaments and microtubules in a neuronal growth cone. J. Cell Biol. 107, 1505-1516. doi: 10.1083/jcb.107.4.1505

Franco, S. J., and Huttenlocher, A. (2005). Regulating cell migration: calpains make the cut. J. Cell Sci. 118, 3829-3838. doi: 10.1242/jcs.02562

Franze, K. (2011). Atomic force microscopy and its contribution to understanding the development of the nervous system. Curr. Opin. Genet. Dev. 21, 530-537. doi: 10.1016/j.gde.2011.07.001

Franze, K. (2013). The mechanical control of nervous system development. Development 140, 3069-3077. doi: 10.1242/dev.079145

Franze, K., Gerdelmann, J., Weick, M., Betz, T., Pawlizak, S., Lakadamyali, M., et al. (2009). Neurite branch retraction is caused by a threshold-dependent mechanical impact. Biophys. J. 97, 1883-1890. doi: 10.1016/j.bpj.2009.07.033

Friedland, J. C., Lee, M. H., and Boettiger, D. (2009). Mechanically activated integrin switch controls alpha5betal function. Science 323, 642-644. doi: 10. 1126/science. 1168441

Furuike, S., Ito, T., and Yamazaki, M. (2001). Mechanical unfolding of single filamin A (ABP-280) molecules detected by atomic force microscopy. FEBS Lett. 498, 72-75. doi: 10.1016/s0014-5793(01)02497-8

Gardel, M. L., Sabass, B., Ji, L., Danuser, G., Schwarz, U. S., and Waterman, C. M. (2008). Traction stress in focal adhesions correlates biphasically with actin retrograde flow speed. J. Cell Biol. 183, 999-1005. doi: 10.1083/jcb.200810060

Gauthier, N. C., Fardin, M. A., Roca-Cusachs, P., and Sheetz, M. P. (2011). Temporary increase in plasma membrane tension coordinates the activation of exocytosis and contraction during cell spreading. Proc. Natl. Acad. Sci. U S A 108, 14467-14472. doi: 10.1073/pnas.1105845108

Geffeney, S. L., and Goodman, M. B. (2012). How we feel: ion channel partnerships that detect mechanical inputs and give rise to touch and pain perception. Neuron 74, 609-619. doi: 10.1016/j.neuron.2012.04.023

Geiger, B., Bershadsky, A., Pankov, R., and Yamada, K. M. (2001). Transmembrane crosstalk between the extracellular matrix-cytoskeleton crosstalk. Nat. Rev. Mol. Cell Biol. 2, 793-805. doi: 10.1038/35099066

Geiger, B., Spatz, J. P., and Bershadsky, A. D. (2009). Environmental sensing through focal adhesions. Nat. Rev. Mol. Cell Biol. 10, 21-33. doi: 10. 1038/nrm2593

Georges, P. C., Miller, W. J., Meaney, D. F., Sawyer, E. S., and Janmey, P. A. (2006). Matrices with compliance comparable to that of brain tissue select neuronal over glial growth in mixed cortical cultures. Biophys. J. 90, 3012-3018. doi: 10. 1529/biophysj.105.073114

Giannone, G., Mège, R. M., and Thoumine, O. (2009). Multi-level molecular clutches in motile cell processes. Trends Cell Biol. 19, 475-486. doi: 10.1016/j. tcb.2009.07.001

Gilmour, D., Knaut, H., Maischein, H. M., and Nusslein-Volhard, C. (2004). Towing of sensory axons by their migrating target cells in vivo. Nat. Neurosci. 7, 491-492. doi: 10.1038/nn1235 
Gomez, T. M., and Letourneau, P. C. (1994). Filopodia initiate choices made by sensory neuron growth cones at laminin/fibronectin borders in vitro. J. Neurosci. 14, 5959-5972.

Gomez, T. M., and Letourneau, P. C. (2014). Actin dynamics in growth cone motility and navigation. J. Neurochem. 129, 221-234. doi: 10.1111/jnc.12506

Gomez, T. M., Robles, E., Poo, M., and Spitzer, N. C. (2001). Filopodial calcium transients promote substrate-dependent growth cone turning. Science 291, 1983-1987. doi: 10.1126/science. 1056490

Gomez, T. M., Roche, F. K., and Letourneau, P. C. (1996). Chick sensory neuronal growth cones distinguish fibronectin from laminin by making substratum contacts that resemble focal contacts. J. Neurobiol. 29, 18-34. doi: 10.1002/(sici)1097-4695(199601)29:1<18::aid-neu2>3.0.co;2-a

Gomez, T. M., and Zheng, J. Q. (2006). The molecular basis for calcium-dependent axon pathfinding. Nat. Rev. Neurosci. 7, 115-125. doi: 10.1038/nrn1844

Gomis, A., Soriano, S., Belmonte, C., and Viana, F. (2008). Hypoosmotic- and pressure-induced membrane stretch activate TRPC5 channels. J. Physiol. 586, 5633-5649. doi: 10.1113/jphysiol.2008.161257

Goswami, C., Kuhn, J., Heppenstall, P. A., and Hucho, T. (2010). Importance of non-selective cation channel TRPV4 interaction with cytoskeleton and their reciprocal regulations in cultured cells. PLoS One 5:e11654. doi: 10. 1371/journal.pone.0011654

Granato, M., van Eeden, F. J., Schach, U., Trowe, T., Brand, M., Furutani-Seiki, M., et al. (1996). Genes controlling and mediating locomotion behavior of the zebrafish embryo and larva. Development 123, 399-413.

Greka, A., Navarro, B., Oancea, E., Duggan, A., and Clapham, D. E. (2003). TRPC5 is a regulator of hippocampal neurite length and growth cone morphology. Nat. Neurosci. 6, 837-845. doi: 10.1038/nn1092

Hammarback, J. A., and Letourneau, P. C. (1986). Neurite extension across regions of low cell-substratum adhesivity: implications for the guidepost hypothesis of axonal pathfinding. Dev. Biol. 117, 655-662. doi: 10.1016/0012-1606(86) 90334-9

Hammarback, J. A., Palm, S. L., Furcht, L. T., and Letourneau, P. C. (1985). Guidance of neurite outgrowth by pathways of substratum-adsorbed laminin. J. Neurosci. Res. 13, 213-220. doi: 10.1002/jnr.490130115

Hattori, M., Osterfield, M., and Flanagan, J. G. (2000). Regulated cleavage of a contact-mediated axon repellent. Science 289, 1360-1365. doi: 10.1126/science. 289.5483.1360

Hayakawa, K., Tatsumi, H., and Sokabe, M. (2008). Actin stress fibers transmit and focus force to activate mechanosensitive channels. J. Cell Sci. 121, 496-503. doi: 10.1242/jcs.022053

Heidemann, S. R., Lamoureux, P., and Buxbaum, R. E. (1990). Growth cone behavior and production of traction force. J. Cell Biol. 111, 1949-1957. doi: 10. 1083/jcb.111.5.1949

Hines, J. H., Abu-Rub, M., and Henley, J. R. (2010). Asymmetric endocytosis and remodeling of betal-integrin adhesions during growth cone chemorepulsion by MAG. Nat. Neurosci. 13, 829-837. doi: 10.1038/nn.2554

Hopkins, A. M., De Laporte, L., Tortelli, F., Spedden, E., Staii, C., Atherton, T. J., et al. (2013). Silk hydrogels as soft substrates for neural tissue engineering. $A d v$. Funct. Mater. 23, 5140-5149. doi: 10.1002/adfm.201300435

Houk, A. R., Jilkine, A., Mejean, C. O., Boltyanskiy, R., Dufresne, E. R., Angenent, S. B., et al. (2012). Membrane tension maintains cell polarity by confining signals to the leading edge during neutrophil migration. Cell 148, 175-188. doi: $10.1016 /$ j.cell.2011.10.050

$\mathrm{Hu}, \mathrm{H}$. (2001). Cell-surface heparan sulfate is involved in the repulsive guidance activities of Slit2 protein. Nat. Neurosci. 4, 695-701. doi: 10.1038/89482

Huang, Z., Yazdani, U., Thompson-Peer, K. L., Kolodkin, A. L., and Terman, J. R. (2007). Crk-associated substrate (Cas) signaling protein functions with integrins to specify axon guidance during development. Development 134, 2337-2347. doi: 10.1242/dev.004242

Hui, H., McHugh, D., Hannan, M., Zeng, F., Xu, S. Z., Khan, S. U., et al. (2006). Calcium-sensing mechanism in TRPC5 channels contributing to retardation of neurite outgrowth. J. Physiol. 572, 165-172. doi: 10.1113/jphysiol.2005. 102889

Humphries, J. D., Paul, N. R., Humphries, M. J., and Morgan, M. R. (2015). Emerging properties of adhesion complexes: what are they and what do they do? Trends Cell Biol. doi: 10.1016/j.tcb.2015.02.008 [Epub ahead of print].

Hyland, C., Mertz, A. F., Forscher, P., and Dufresne, E. (2014). Dynamic peripheral traction forces balance stable neurite tension in regenerating Aplysia bag cell neurons. Sci. Rep. 4:4961. doi: 10.1038/srep04961
Hynes, R. O. (2002). Integrins: bidirectional, allosteric signaling machines. Cell 110, 673-687. doi: 10.1016/S0092-8674(02)00971-6

Hynes, R. O. (2009). The extracellular matrix: not just pretty fibrils. Science 326, 1216-1219. doi: 10.1126/science.1176009

Hynes, R. O., and Naba, A. (2012). Overview of the matrisome-an inventory of extracellular matrix constituents and functions. Cold Spring Harb. Perspect. Biol. 4:a004903. doi: 10.1101/cshperspect.a004903

Isacson, O., Deacon, T. W., Pakzaban, P., Galpern, W. R., Dinsmore, J., and Burns, L. H. (1995). Transplanted xenogeneic neural cells in neurodegenerative disease models exhibit remarkable axonal target specificity and distinct growth patterns of glial and axonal fibres. Nat. Med. 1, 1189-1194. doi: 10. 1038/nm1195-1189

Iwashita, M., Kataoka, N., Toida, K., and Kosodo, Y. (2014). Systematic profiling of spatiotemporal tissue and cellular stiffness in the developing brain. Development 141, 3793-3798. doi: 10.1242/dev.109637

Jacques-Fricke, B. T., Seow, Y., Gottlieb, P. A., Sachs, F., and Gomez, T. M. (2006). $\mathrm{Ca} 2+$ influx through mechanosensitive channels inhibits neurite outgrowth in opposition to other influx pathways and release from intracellular stores. $J$. Neurosci. 26, 5656-5664. doi: 10.1523/jneurosci.0675-06.2006

Jiang, F. X., Yurke, B., Firestein, B. L., and Langrana, N. A. (2008). Neurite outgrowth on a DNA crosslinked hydrogel with tunable stiffnesses. Ann. Biomed. Eng. 36, 1565-1579. doi: 10.1007/s10439-008-9530-z

Kang, H., and Lichtman, J. W. (2013). Motor axon regeneration and muscle reinnervation in young adult and aged animals. J. Neurosci. 33, 19480-19491. doi: 10.1523/JNEUROSCI.4067-13.2013

Kazmierczak, P., and Müller, U. (2012). Sensing sound: molecules that orchestrate mechanotransduction by hair cells. Trends Neurosci. 35, 220-229. doi: 10. 1016/j.tins.2011.10.007

Kerstein, P. C., Jacques-Fricke, B. T., Rengifo, J., Mogen, B. J., Williams, J. C., Gottlieb, P. A., et al. (2013). Mechanosensitive TRPC1 channels promote calpain proteolysis of talin to regulate spinal axon outgrowth. J. Neurosci. 33, 273-285. doi: 10.1523/JNEUROSCI.2142-12.2013

Keynes, R. J., and Stern, C. D. (1984). Segmentation in the vertebrate nervous system. Nature 310, 786-789. doi: 10.1038/310786a0

Kim, S. N., Jeibmann, A., Halama, K., Witte, H. T., Wälte, M., Matzat, T., et al. (2014). ECM stiffness regulates glial migration in Drosophila and mammalian glioma models. Development 141, 3233-3242. doi: 10.1242/dev. 106039

Kim, T. J., Seong, J., Ouyang, M., Sun, J., Lu, S., Hong, J. P., et al. (2009). Substrate rigidity regulates $\mathrm{Ca}+$ oscillation via RhoA pathway in stem cells. J. Cell Physiol. 218, 285-293. doi: 10.1002/jcp.21598

Kobayashi, T., and Sokabe, M. (2010). Sensing substrate rigidity by mechanosensitive ion channels with stress fibers and focal adhesions. Curr. Opin. Cell Biol. 22, 669-676. doi: 10.1016/j.ceb.2010.08.023

Koch, D., Rosoff, W. J., Jiang, J., Geller, H. M., and Urbach, J. S. (2012). Strength in the periphery: growth cone biomechanics and substrate rigidity response in peripheral and central nervous system neurons. Biophys. J. 102, 452-460. doi: 10.1016/j.bpj.2011.12.025

Kolodkin, A. L., and Tessier-Lavigne, M. (2011). Mechanisms and molecules of neuronal wiring: a primer. Cold Spring Harb. Perspect. Biol. 3:a001727. doi: 10. 1101/cshperspect.a001727

Kostic, A., Sap, J., and Sheetz, M. P. (2007). RPTPalpha is required for rigiditydependent inhibition of extension and differentiation of hippocampal neurons. J. Cell Sci. 120, 3895-3904. doi: 10.1242/jcs.009852

Kruse, S. A., Rose, G. H., Glaser, K. J., Manduca, A., Felmlee, J. P., Jack, C. R. Jr., et al. (2008). Magnetic resonance elastography of the brain. Neuroimage 39, 231-237. doi: 10.1016/j.neuroimage.2007.08.030

Kubota, H., Ishikawa, R., Ohki, T., Ishizuka, J., Mikhailenko, S. V., and Ishiwata, S. (2010). Modulation of the mechano-chemical properties of myosin $\mathrm{V}$ by drebrin-E. Biochem. Biophys. Res. Commun. 400, 643-648. doi: 10.1016/j.bbrc. 2010.08.120

Kuo, J. C., Han, X., Yates, J. R., III, and Waterman, C. M. (2012). Isolation of focal adhesion proteins for biochemical and proteomic analysis. Methods Mol. Biol. 757, 297-323. doi: 10.1007/978-1-61779-166-6_19

Lagenaur, C., and Lemmon, V. (1987). An L1-like molecule, the 8D9 antigen, is a potent substrate for neurite extension. Proc. Natl. Acad. Sci. U S A 84, 7753-7757. doi: 10.1073/pnas.84.21.7753

Lamoureux, P., Buxbaum, R. E., and Heidemann, S. R. (1989). Direct evidence that growth cones pull. Nature 340, 159-162. doi: 10.1038/340159a0 
Lee, J., Ishihara, A., Oxford, G., Johnson, B., and Jacobson, K. (1999). Regulation of cell movement is mediated by stretch-activated calcium channels. Nature 400, 382-386. doi: 10.1038/22578

Letourneau, P. C., Shattuck, T. A., and Ressler, A. H. (1987). "Pull” and "push" in neurite elongation: observations on the effects of different concentrations of cytochalasin B and taxol. Cell Motil. Cytoskeleton 8, 193-209. doi: 10.1002/cm. 970080302

Li, J., Gu, X., Ma, Y., Calicchio, M. L., Kong, D., Teng, Y. D., et al. (2010). Nnal mediates Purkinje cell dendritic development via lysyl oxidase propeptide and NF-kappaB signaling. Neuron 68, 45-60. doi: 10.1016/j.neuron.2010. 08.013

Li, Y., Jia, Y. C., Cui, K., Li, N., Zheng, Z. Y., Wang, Y. Z., et al. (2005). Essential role of TRPC channels in the guidance of nerve growth cones by brain-derived neurotrophic factor. Nature 434, 894-898. doi: 10.1038/nature03477

Lin, C. H., and Forscher, P. (1995). Growth cone advance is inversely proportional to retrograde F-actin flow. Neuron 14, 763-771. doi: 10. 1016/0896-6273(95)90220-1

Lin, C. H., Espreafico, E. M., Mooseker, M. S., and Forscher, P. (1996). Myosin drives retrograde F-actin flow in neuronal growth cones. Neuron 16, 769-782. doi: 10.1016/s0896-6273(00)80097-5

Liu, C., and Montell, C. (2015). Forcing open TRP channels: Mechanical gating as a unifying activation mechanism. Biochem. Biophys. Res. Commun. 460, 22-25. doi: 10.1016/j.bbrc.2015.02.067

Lo, C. M., Wang, H. B., Dembo, M., and Wang, Y. L. (2000). Cell movement is guided by the rigidity of the substrate. Biophys. J. 79, 144-152. doi: 10 . 1016/s0006-3495(00)76279-5

Lowery, L. A., and van Vactor, D. (2009). The trip of the tip: understanding the growth cone machinery. Nat. Rev. Mol. Cell Biol. 10, 332-343. doi: 10. $1038 / \mathrm{nrm} 2679$

Lu, Y. B., Franze, K., Seifert, G., Steinhäuser, C., Kirchhoff, F., Wolburg, H., et al. (2006). Viscoelastic properties of individual glial cells and neurons in the CNS. Proc. Natl. Acad. Sci. U S A 103, 17759-17764. doi: 10.1073/pnas.06061 50103

Mai, J., Fok, L., Gao, H., Zhang, X., and Poo, M. M. (2009). Axon initiation and growth cone turning on bound protein gradients. J. Neurosci. 29, 7450-7458. doi: 10.1523/JNEUROSCI.1121-09.2009

Manitt, C., and Kennedy, T. E. (2002). Where the rubber meets the road: netrin expression and function in developing and adult nervous systems. Prog. Brain Res. 137, 425-442. doi: 10.1016/s0079-6123(02)37034-1

Margadant, F., Chew, L. L., Hu, X., Yu, H., Bate, N., Zhang, X., et al. (2011). Mechanotransduction in vivo by repeated talin stretch-relaxation events depends upon vinculin. PLoS Biol. 9:e1001223. doi: 10.1371/journal.pbio. 1001223

Maroto, R., Raso, A., Wood, T. G., Kurosky, A., Martinac, B., and Hamill, O. P. (2005). TRPC1 forms the stretch-activated cation channel in vertebrate cells. Nat. Cell Biol. 7, 179-185. doi: 10.1038/ncb1218

Marsick, B. M., Flynn, K. C., Santiago-Medina, M., Bamburg, J. R., and Letourneau, P. C. (2010). Activation of ADF/cofilin mediates attractive growth cone turning toward nerve growth factor and netrin-1. Dev. Neurobiol. 70, 565-588. doi: 10.1002/dneu.20800

Matthews, B. D., Thodeti, C. K., Tytell, J. D., Mammoto, A., Overby, D. R., and Ingber, D. E. (2010). Ultra-rapid activation of TRPV4 ion channels by mechanical forces applied to cell surface betal integrins. Integr. Biol. (Camb) 2, 435-442. doi: 10.1039/c0ib00034e

McHugh, B. J., Buttery, R., Lad, Y., Banks, S., Haslett, C., and Sethi, T. (2010). Integrin activation by Fam38A uses a novel mechanism of R-Ras targeting to the endoplasmic reticulum. J. Cell Sci. 123, 51-61. doi: 10.1242/jcs. 056424

McHugh, B. J., Murdoch, A., Haslett, C., and Sethi, T. (2012). Loss of the integrinactivating transmembrane protein Fam38A (Piezo1) promotes a switch to a reduced integrin-dependent mode of cell migration. PLoS One 7:e40346. doi: 10.1371/journal.pone.0040346

Medeiros, N. A., Burnette, D. T., and Forscher, P. (2006). Myosin II functions in actin-bundle turnover in neuronal growth cones. Nat. Cell Biol. 8, 215-226. doi: $10.1038 /$ ncb1367

Mingorance-Le Meur, A., and O'connor, T. P. (2009). Neurite consolidation is an active process requiring constant repression of protrusive activity. EMBO J. 28, 248-260. doi: 10.1038/emboj.2008.265
Mogilner, A., and Oster, G. (2003). Polymer motors: pushing out the front and pulling up the back. Curr. Biol. 13, R721-R733. doi: 10.1016/j.cub.2003.08.050

Moore, S. W., Biais, N., and Sheetz, M. P. (2009). Traction on immobilized netrin-1 is sufficient to reorient axons. Science 325:166. doi: 10.1126/science.1173851

Moore, S. W., Roca-Cusachs, P., and Sheetz, M. P. (2010). Stretchy proteins on stretchy substrates: the important elements of integrin-mediated rigidity sensing. Dev. Cell 19, 194-206. doi: 10.1016/j.devcel.2010.07.018

Moore, S. W., and Sheetz, M. P. (2011). Biophysics of substrate interaction: influence on neural motility, differentiation and repair. Dev. Neurobiol. 71, 1090-1101. doi: 10.1002/dneu.20947

Moore, S. W., Zhang, X., Lynch, C. D., and Sheetz, M. P. (2012). Netrin-1 attracts axons through FAK-dependent mechanotransduction. J. Neurosci. 32, 11574-11585. doi: 10.1523/JNEUROSCI.0999-12.2012

Munevar, S., Wang, Y. L., and Dembo, M. (2004). Regulation of mechanical interactions between fibroblasts and the substratum by stretch-activated $\mathrm{Ca} 2+$ entry. J. Cell Sci. 117, 85-92. doi: 10.1242/jcs.00795

Musah, S., Wrighton, P. J., Zaltsman, Y., Zhong, X., Zorn, S., Parlato, M. B., et al. (2014). Substratum-induced differentiation of human pluripotent stem cells reveals the coactivator YAP is a potent regulator of neuronal specification. Proc. Natl. Acad. Sci. U S A 111, 13805-13810. doi: 10.1073/pnas.14153 30111

Myers, J. P., and Gomez, T. M. (2011). Focal adhesion kinase promotes integrin adhesion dynamics necessary for chemotropic turning of nerve growth cones. J. Neurosci. 31, 13585-13595. doi: 10.1523/JNEUROSCI.2381-11.2011

Myers, J. P., Robles, E., Ducharme-Smith, A., and Gomez, T. M. (2012). Focal adhesion kinase modulates Cdc42 activity downstream of positive and negative axon guidance cues. J. Cell Sci. 125(Pt. 12), 2918-2929. doi: 10.1242/jcs. 100107

Myers, J. P., Santiago-Medina, M., and Gomez, T. M. (2011). Regulation of axonal outgrowth and pathfinding by integrin-ECM interactions. Dev. Neurobiol. 71, 901-923. doi: 10.1002/dneu.20931

Nakamura, F., Kumeta, K., Hida, T., Isono, T., Nakayama, Y., KuramataMatsuoka, E., et al. (2014). Amino- and carboxyl-terminal domains of FilaminA interact with CRMP1 to mediate Sema3A signalling. Nat. Commun. 5:5325. doi: 10.1038/ncomms6325

Nguyen, Q. T., Sanes, J. R., and Lichtman, J. W. (2002). Pre-existing pathways promote precise projection patterns. Nat. Neurosci. 5, 861-867. doi: 10 1038/nn905

O'Connor, T. P., Duerr, J. S., and Bentley, D. (1990). Pioneer growth cone steering decisions mediated by single filopodial contacts in situ. J. Neurosci. 10, 3935-3946.

Oancea, E., Wolfe, J. T., and Clapham, D. E. (2006). Functional TRPM7 channels accumulate at the plasma membrane in response to fluid flow. Circ. Res. 98, 245-253. doi: 10.1161/01.res.0000200179.29375.cc

Paszek, M. J., Zahir, N., Johnson, K. R., Lakins, J. N., Rozenberg, G. I., Gefen, A., et al. (2005). Tensional homeostasis and the malignant phenotype. Cancer Cell 8, 241-254. doi: 10.1016/j.ccr.2005.08.010

Paulus, J. D., Willer, G. B., Willer, J. R., Gregg, R. G., and Halloran, M. C. (2009). Muscle contractions guide rohon-beard peripheral sensory axons. J. Neurosci. 29, 13190-13201. doi: 10.1523/JNEUROSCI.2179-09.2009

Pelham, R. J. Jr., and Wang, Y. I. (1997). Cell locomotion and focal adhesions are regulated by substrate flexibility. Proc. Natl. Acad. Sci. U S A 94, 13661-13665. doi: 10.1073/pnas.94.25.13661

Plotnikov, S. V., Pasapera, A. M., Sabass, B., and Waterman, C. M. (2012). Force fluctuations within focal adhesions mediate ECM-rigidity sensing to guide directed cell migration. Cell 151, 1513-1527. doi: 10.1016/j.cell.2012.11.034

Provenzano, P. P., Inman, D. R., Eliceiri, K. W., and Keely, P. J. (2009). Matrix density-induced mechanoregulation of breast cell phenotype, signaling and gene expression through a FAK-ERK linkage. Oncogene 28, 4326-4343. doi: 10. 1038/onc.2009.299

Rahman, S., Patel, Y., Murray, J., Patel, K. V., Sumathipala, R., Sobel, M., et al. (2005). Novel hepatocyte growth factor (HGF) binding domains on fibronectin and vitronectin coordinate a distinct and amplified Met-integrin induced signalling pathway in endothelial cells. BMC Cell Biol. 6:8. doi: 10.1186/14712121-6-8

Ranade, S. S., Woo, S. H., Dubin, A. E., Moshourab, R. A., Wetzel, C., Petrus, M., et al. (2014). Piezo2 is the major transducer of mechanical forces for touch sensation in mice. Nature 516, 121-125. doi: 10.1038/nature13980 
Razinia, Z., Mäkelä, T., Ylänne, J., and Calderwood, D. A. (2012). Filamins in mechanosensing and signaling. Annu. Rev. Biophys. 41, 227-246. doi: 10. 1146/annurev-biophys-050511-102252

Riccio, A., Medhurst, A. D., Mattei, C., Kelsell, R. E., Calver, A. R., Randall, A. D., et al. (2002). mRNA distribution analysis of human TRPC family in CNS and peripheral tissues. Brain Res. Mol. Brain Res. 109, 95-104. doi: 10.1016/s0169$328 \mathrm{x}(02) 00527-2$

Riccomagno, M. M., Sun, L. O., Brady, C. M., Alexandropoulos, K., Seo, S., Kurokawa, M., et al. (2014). Cas adaptor proteins organize the retinal ganglion cell layer downstream of integrin signaling. Neuron 81, 779-786. doi: 10.1016/j. neuron.2014.01.036

Robles, E., and Gomez, T. M. (2006). Focal adhesion kinase signaling at sites of integrin-mediated adhesion controls axon pathfinding. Nat. Neurosci. 9, 1274-1283. doi: $10.1038 / \mathrm{nn} 1762$

Robles, E., Huttenlocher, A., and Gomez, T. M. (2003). Filopodial calcium transients regulate growth cone motility and guidance through local activation of calpain. Neuron 38, 597-609. doi: 10.1016/s0896-6273(03)00260-5

Rutishauser, U. (1985). Influences of the neural cell adhesion molecule on axon growth and guidance. J. Neurosci. Res. 13, 123-131. doi: 10.1002/jnr.490130109

Santiago-Medina, M., Gregus, K. A., and Gomez, T. M. (2013). PAK-PIX interactions regulate adhesion dynamics and membrane protrusion to control neurite outgrowth. J. Cell Sci. 126, 1122-1133. doi: 10.1242/jcs.112607

Santiago-Medina, M., Gregus, K. A., Nichol, R. H., O’Toole, S. M., and Gomez, T. M. (2015). Regulation of ECM degradation and axon guidance by growth cone invadosomes. Development 142, 486-496. doi: 10.1242/dev.108266

Sawada, Y., Tamada, M., Dubin-Thaler, B. J., Cherniavskaya, O., Sakai, R., Tanaka, S., et al. (2006). Force sensing by mechanical extension of the Src family kinase substrate p130Cas. Cell 127, 1015-1026. doi: 10.1016/j.cell.2006.09.044

Schedin, P., and Keely, P. J. (2011). Mammary gland ECM remodeling, stiffness and mechanosignaling in normal development and tumor progression. Cold Spring Harb. Perspect. Biol. 3:a003228. doi: 10.1101/cshperspect.a003228

Schmidt, C. E., Dai, J., Lauffenburger, D. A., Sheetz, M. P., and Horwitz, A. F. (1995). Integrin-cytoskeletal interactions in neuronal growth cones. J. Neurosci. 15, 3400-3407.

Schneider, V. A., and Granato, M. (2006). The myotomal diwanka (lh3) glycosyltransferase and type XVIII collagen are critical for motor growth cone migration. Neuron 50, 683-695. doi: 10.1016/j.neuron.2006.04.024

Shibasaki, K., Murayama, N., Ono, K., Ishizaki, Y., and Tominaga, M. (2010). TRPV2 enhances axon outgrowth through its activation by membrane stretch in developing sensory and motor neurons. J. Neurosci. 30, 4601-4612. doi: 10. 1523/JNEUROSCI.5830-09.2010

Shigeoka, T., Lu, B., and Holt, C. E. (2013). Cell biology in neuroscience: RNAbased mechanisms underlying axon guidance. J. Cell Biol. 202, 991-999. doi: 10. 1083/jcb.201305139

Shim, S., Goh, E. L., Ge, S. Y., Sailor, K., Yuan, J. P., Roderick, H. L., et al. (2005). XTRPC1-dependent chemotropic guidance of neuronal growth cones. Nat. Neurosci. 8, 730-735. doi: 10.1038/nn1459

Shimada, T., Toriyama, M., Uemura, K., Kamiguchi, H., Sugiura, T., Watanabe, N., et al. (2008). Shootin1 interacts with actin retrograde flow and L1-CAM to promote axon outgrowth. J. Cell Biol. 181, 817-829. doi: 10.1083/jcb.200712138

Shin, E. Y., Lee, C. S., Yun, C. Y., Won, S. Y., Kim, H. K., Lee, Y. H., et al. (2014). Non-muscle myosin II regulates neuronal actin dynamics by interacting with guanine nucleotide exchange factors. PLoS One 9:e95212. doi: 10.1371/journal. pone.0095212

Smilenov, L. B., Mikhailov, A., Pelham, R. J., Marcantonio, E. E., and Gundersen, G. G. (1999). Focal adhesion motility revealed in stationary fibroblasts. Science 286, 1172-1174. doi: 10.1126/science.286.5442.1172

Spassova, M. A., Hewavitharana, T., Xu, W., Soboloff, J., and Gill, D. L. (2006). A common mechanism underlies stretch activation and receptor activation of TRPC6 channels. Proc. Natl. Acad. Sci. U S A 103, 16586-16591. doi: 10. 1073/pnas.0606894103

Strübing, C., Krapivinsky, G., Krapivinsky, L., and Clapham, D. E. (2003). Formation of novel TRPC channels by complex subunit interactions in embryonic brain. J. Biol. Chem. 278, 39014-39019. doi: 10.1074/jbc. m306705200

Sundararaghavan, H. G., Monteiro, G. A., Firestein, B. L., and Shreiber, D. I. (2009). Neurite growth in 3D collagen gels with gradients of mechanical properties. Biotechnol. Bioeng. 102, 632-643. doi: 10.1002/bit.22074
Suter, D. M., Errante, L. D., Belotserkovsky, V., and Forscher, P. (1998). The Ig superfamily cell adhesion molecule, apCAM, mediates growth cone steering by substrate-cytoskeletal coupling. J. Cell Biol. 141, 227-240. doi: 10.1083/jcb.141. 1.227

Suter, D. M., Espindola, F. S., Lin, C. H., Forscher, P., and Mooseker, M. S. (2000). Localization of unconventional myosins $\mathrm{V}$ and VI in neuronal growth cones. J. Neurobiol. 42, 370-382. doi: 10.1002/(sici)1097-4695(20000215)42:3<370::aidneu8 $>3.3 . c 0 ; 2-m$

Sydor, A. M., Su, A. L., Wang, F. S., Xu, A., and Jay, D. G. (1996). Talin and vinculin play distinct roles in filopodial motility in the neuronal growth cone. J. Cell Biol. 134, 1197-1207. doi: 10.1083/jcb.134.5.1197

Symons, M. H., and Mitchison, T. J. (1991). Control of actin polymerization in live and permeabilized fibroblasts. J. Cell Biol. 114, 503-513. doi: 10.1083/jcb.114. 3.503

Thievessen, I., Thompson, P. M., Berlemont, S., Plevock, K. M., Plotnikov, S. V., Zemljic-Harpf, A., et al. (2013). Vinculin-actin interaction couples actin retrograde flow to focal adhesions, but is dispensable for focal adhesion growth. J. Cell Biol. 202, 163-177. doi: 10.1083/jcb.201303129

Tojima, T., Akiyama, H., Itofusa, R., Li, Y., Katayama, H., Miyawaki, A., et al. (2007). Attractive axon guidance involves asymmetric membrane transport and exocytosis in the growth cone. Nat. Neurosci. 10, 58-66. doi: 10.1038/ nn1814

Tojima, T., Itofusa, R., and Kamiguchi, H. (2010). Asymmetric clathrin-mediated endocytosis drives repulsive growth cone guidance. Neuron 66, 370-377. doi: 10.1016/j.neuron.2010.04.007

Tojima, T., Itofusa, R., and Kamiguchi, H. (2014). Steering neuronal growth cones by shifting the imbalance between exocytosis and endocytosis. J. Neurosci. 34, 7165-7178. doi: 10.1523/JNEUROSCI.5261-13.2014

Toriyama, M., Kozawa, S., Sakumura, Y., and Inagaki, N. (2013). Conversion of a signal into forces for axon outgrowth through Pak1-mediated shootin1 phosphorylation. Curr. Biol. 23, 529-534. doi: 10.1016/j.cub.2013. 02.017

Turlova, E., Bae, C. Y., Deurloo, M., Chen, W., Barszczyk, A., Horgen, F. D., et al. (2014). TRPM7 Regulates Axonal Outgrowth and Maturation of Primary Hippocampal Neurons. Mol. Neurobiol. doi: 10.1007/s12035-014-9032-y [Epub ahead of print].

Turney, S. G., and Bridgman, P. C. (2005). Laminin stimulates and guides axonal outgrowth via growth cone myosin II activity. Nat. Neurosci. 8, 717-719. doi: $10.1038 / \mathrm{nn} 1466$

Tyler, W. J. (2012). The mechanobiology of brain function. Nat. Rev. Neurosci. 13, 867-878. doi: 10.1038/nrn3383

Vitriol, E. A., and Zheng, J. Q. (2012). Growth cone travel in space and time: the cellular ensemble of cytoskeleton, adhesion and membrane. Neuron 73 , 1068-1081. doi: 10.1016/j.neuron.2012.03.005

Von Niederhäusern, V., Kastenhuber, E., Stäuble, A., Gesemann, M., and Neuhauss, S. C. (2013). Phylogeny and expression of canonical transient receptor potential (TRPC) genes in developing zebrafish. Dev. Dyn. 242, 1427-1441. doi: 10.1002/dvdy.24041

von Philipsborn, A. C., Lang, S., Bernard, A., Loeschinger, J., David, C., Lehnert, D., et al. (2006). Microcontact printing of axon guidance molecules for generation of graded patterns. Nat. Protoc. 1, 1322-1328. doi: 10.1038/nprot. 2006.251

Vriens, J., Watanabe, H., Janssens, A., Droogmans, G., Voets, T., and Nilius, B. (2004). Cell swelling, heat and chemical agonists use distinct pathways for the activation of the cation channel TRPV4. Proc. Natl. Acad. Sci. U S A 101, 396-401. doi: 10.1073/pnas.0303329101

Wang, H. B., Dembo, M., Hanks, S. K., and Wang, Y. (2001). Focal adhesion kinase is involved in mechanosensing during fibroblast migration. Proc. Natl. Acad. Sci. U S A 98, 11295-11300. doi: 10.1073/pnas.201201198

Wang, F. S., Liu, C. W., Diefenbach, T. J., and Jay, D. G. (2003). Modeling the role of myosin 1c in neuronal growth cone turning. Biophys. J. 85, 3319-3328. doi: 10.1016/s0006-3495(03)74751-1

Wang, G. X., and Poo, M. M. (2005). Requirement of TRPC channels in netrin1 -induced chemotropic turning of nerve growth cones. Nature 434, 898-904. doi: $10.1038 /$ nature 03478

Wei, C., Wang, X., Chen, M., Ouyang, K., Song, L. S., and Cheng, H. (2009). Calcium flickers steer cell migration. Nature 457, 901-905. doi: 10. 1038/nature07577 
Weinl, C., Drescher, U., Lang, S., Bonhoeffer, F., and Löschinger, J. (2003). On the turning of Xenopus retinal axons induced by ephrin-A5. Development 130, 1635-1643. doi: 10.1242/dev.00386

Wen, Z., Guirland, C., Ming, G. L., and Zheng, J. Q. (2004). A CaMKII/calcineurin switch controls the direction of $\mathrm{Ca}(2+)$-dependent growth cone guidance. Neuron 43, 835-846. doi: 10.1016/j.neuron.2004.08.037

Wen, Z., Han, L., Bamburg, J. R., Shim, S., Ming, G. L., and Zheng, J. Q. (2007). BMP gradients steer nerve growth cones by a balancing act of LIM kinase and Slingshot phosphatase on ADF/cofilin. J. Cell Biol. 178, 107-119. doi: 10. $1083 /$ jcb. 200703055

Willits, R. K., and Skornia, S. L. (2004). Effect of collagen gel stiffness on neurite extension. J. Biomater. Sci. Polym. Ed. 15, 1521-1531. doi: 10. $1163 / 1568562042459698$

Winkle, C. C., McClain, L. M., Valtschanoff, J. G., Park, C. S., Maglione, C., and Gupton, S. L. (2014). A novel Netrin-1-sensitive mechanism promotes local SNARE-mediated exocytosis during axon branching. J. Cell Biol. 205, 217-232. doi: $10.1083 /$ jcb. 201311003

Woo, S., and Gomez, T. M. (2006). Racl and RhoA promote neurite outgrowth through formation and stabilization of growth cone point contacts. J. Neurosci. 26, 1418-1428. doi: 10.1523/jneurosci.4209-05.2006

Woo, S., Rowan, D. J., and Gomez, T. M. (2009). Retinotopic mapping requires focal adhesion kinase-mediated regulation of growth cone adhesion. J. Neurosci. 29, 13981-13991. doi: 10.1523/JNEUROSCI.4028-09. 2009

Woo, S. H., Ranade, S., Weyer, A. D., Dubin, A. E., Baba, Y., Qiu, Z., et al. (2014). Piezo2 is required for Merkel-cell mechanotransduction. Nature 509, 622-626. doi: 10.1038/nature13251

Wright, K. M., Lyon, K. A., Leung, H., Leahy, D. J., Ma, L., and Ginty, D. D. (2012). Dystroglycan organizes axon guidance cue localization and axonal pathfinding. Neuron 76, 931-944. doi: 10.1016/j.neuron.2012.10.009

Wu, G., Lu, Z. H., Obukhov, A. G., Nowycky, M. C., and Ledeen, R. W. (2007). Induction of calcium influx through TRPC5 channels by crosslinking of GM1 ganglioside associated with alpha5betal integrin initiates neurite outgrowth. J. Neurosci. 27, 7447-7458. doi: 10.1523/jneurosci.4266-06. 2007
Wu, L. J., Sweet, T. B., and Clapham, D. E. (2010). International union of basic and clinical pharmacology. LXXVI. Current progress in the mammalian TRP ion channel family. Pharmacol. Rev. 62, 381-404. doi: 10.1124/pr.110.002725

Xiao, T., Staub, W., Robles, E., Gosse, N. J., Cole, G. J., and Baier, H. (2011). Assembly of lamina-specific neuronal connections by slit bound to type IV collagen. Cell 146, 164-176. doi: 10.1016/j.cell.2011.06.016

Yamauchi, M., and Sricholpech, M. (2012). Lysine post-translational modifications of collagen. Essays Biochem. 52, 113-133. doi: 10 1042/bse0520113

Yang, Q., Zhang, X. F., Van Goor, D., Dunn, A. P., Hyland, C., Medeiros, N., et al. (2013). Protein kinase C activation decreases peripheral actin network density and increases central nonmuscle myosin II contractility in neuronal growth cones. Mol. Biol. Cell 24, 3097-3114. doi: 10.1091/mbc.e1305-0289

Zeller, J., and Granato, M. (1999). The zebrafish diwanka gene controls an early step of motor growth cone migration. Development 126, 3461-3472.

Zhang, X. F., Hyland, C., Van Goor, D., and Forscher, P. (2012). Calcineurindependent cofilin activation and increased retrograde actin flow drive 5-HTdependent neurite outgrowth in Aplysia bag cell neurons. Mol. Biol. Cell 23, 4833-4848. doi: 10.1091/mbc.e12-10-0715

Zheng, L., Michelson, Y., Freger, V., Avraham, Z., Venken, K. J., Bellen, H. J., et al. (2011). Drosophila Ten-m and filamin affect motor neuron growth cone guidance. PLoS One 6:e22956. doi: 10.1371/journal.pone. 0022956

Conflict of Interest Statement: The authors declare that the research was conducted in the absence of any commercial or financial relationships that could be construed as a potential conflict of interest.

Copyright (c) 2015 Kerstein, Nichol and Gomez. This is an open-access article distributed under the terms of the Creative Commons Attribution License (CC BY). The use, distribution and reproduction in other forums is permitted, provided the original author(s) or licensor are credited and that the original publication in this journal is cited, in accordance with accepted academic practice. No use, distribution or reproduction is permitted which does not comply with these terms. 